\title{
Tobacco Control Laws of South Asian Countries: A Quantitative-Comparative Analysis of Compliance with FCTC and their Effects on Smoking Prevalence
}

\author{
Muhammad Shahzad $^{1}$, Anwar Shah ${ }^{2}$, Frank Joseph Chaloupka ${ }^{3}$
}

\begin{abstract}
Smoking has been the topic of research for long time. Scholars have written on this issue from different dimensions like revenue generation, employment creation, environmental and health hazards. However, it exposes a person to more than 400 carcinogenic chemicals, causing many detrimental diseases like lung cancer, coronary artery disease, heart attack, stroke which kill more than 7 million people annually. Due to high smoking attributable mortality and morbidity; the World Health Organization (hereafter WHO) passed Framework Convention on Tobacco Control (hereafter FCTC). WHO-FCTC stipulates certain obligatory rules for the control of smoking prevalence and tobacco hazards to its member states. This paper aimed to examine the compliance of tobacco control laws with the FCTC guidelines and their effects on smoking prevalence in South Asian countries. The work hypothesized that higher compliance of tobacco control laws with the WHO-FCTC rules reduces smoking prevalence. The study employed positivist approach using descriptive statistics to determine the role of compliance with tobacco control laws in controlling of smoking prevalence rates. The study used data from different sources like the official Gazette books, reports of the World Health Organization (WHO), website (tobacco control laws) of the campaign for Tobacco-free Kids, Our World in Data (OWID), population pyramid.net and The World Bank. We compared and contrasted the national laws governing tobacco control in South Asia with the WHO-FCTC guidelines to test our hypothesis. We constructed an overall compliance index for the countries. We found non-compliance with the FCTC proposed tax share and heterogeneities in tax rates among the countries to reduce the smoking prevalence rates. Bangladesh has attained the highest index score of 0.748 followed by Sri Lanka with 0.650 index score whereas, Nepal and India have the least scores on compliance. The least scores of India and Nepal go against our hypothesis because the countries have achieved maximum reduction in tobacco control despite their low scores on the index
\end{abstract}

Keywords: Tobacco control laws, WHO-FCTC, South Asia

1 Ph.D Scholar, School of Economics, Quaid-i-Azam University, Islamabad, Pakistan and faculty member at Department of Economics, University of Swabi. Email: msdresearcher2011@gmail.com

2 Associate Professor, School of Economics, Quaid-i-Azam University, Islamabad, Pakistan.

3 Director, Institute for Health Research and Policy, University of Illinois at Chicago

ARTICLE HISTORY

17 May, 2019 Submission Received

17 Jul, 2019 First Review

17 Oct, 2020 Second Review

17 Nov, 2020 Accepted 


\section{Introduction}

Smoking exposes a person to more than 4000 chemical compounds, out of which more than 400 are reported to have toxic nature. The presence of nicotine in cigarettes makes them highly addictive which in turn causes many detrimental diseases like lung cancer, coronary artery disease, heart attack and stroke (United States Department of Health and Human Services, 2014). Smoking can damage almost any organ in human body, leading to leukemia and cancers of the kidney, pancreas, bladder, throat, mouth and uterus. It can damage the airways and air sacs of lungs to cause chronic bronchitis and breathing difficulties (Islam, Mainuddin, Bhuiyan, \& Choudhry, 2016; O'Donnell, et al., 2016). It can also raise blood pressure and cholesterol levels, reduces bone density in women and increases the risk of infertility, preterm delivery, stillbirth and sudden infant death syndrome (Stanley, 2017). Likewise, active tobacco smoking has been associated with severity of COVID-19 patients. COVID-19 patients with active smoking history are 1.4 times more likely to have severe symptoms and 2.4 times more likely, to need mechanical ventilation and ICU services, or die as compared to non-smokers (Vardavas \& Nikitara, 2020). As the adverse effects of smoking are revealed by a slow and gradual process and smokers have a very low discount rate for the marginal impact of smoking on the health. They value more the satisfaction of the addictive desire than the future health effects. Each time fulfilling the addictive desire, smokers' vulnerability to more addiction and adverse health effects is increased. Although smokers derive utility from smoking but association with increase in mortality risk with the ageing process is also well established. However, the adverse marginal impact is low and smokers fail to realize the health hazards of smoking (Adda \& Lelenche, 2001). The low marginal health impact and far away future consequences has resulted to take the global tobacco prevalence figure to 1.22 billion smokers who smoke almost 18 billion cigarettes sticks daily (The Tobacco Atlas, 2016).

Although efforts for the control of tobacco prevalence were initiated as earlier as in 1890 to address the issue of the then female rising smoking prevalence rates but due to no established link with health, regulations lost momentum (Lessig, 1995). However, it regained its momentum with the report of the US surgeon general, which established causal relation of smoking and various detrimental diseases (Milov, 2019). The spur provided by the report of the US surgeon general attracted the interest of scholars and studies were undertaken to estimate the economic cost of smoking and counter the tactics of tobacco industry. Although developed countries had far higher prevalence of tobacco than developing countries but realized the associated health hazards early and responded with comprehensive tobacco control laws to decrease the smoking prevalence rates successfully (Gneiting \& Schmitz, 2016). Unfortunately, in contrast to the achievements of advanced countries, the story of developing countries 
is otherwise. The tobacco industry shifted their focus towards developing countries for the expansion of their business and profits. In the quest for profits and enlarging their business empires, the big tobacco spread its tentacles in developing countries and ultimately increased the tobacco addiction, incidence of smoking and smoking induced morbidity and mortality (Hooper \& Aglue, 2009). Currently developing countries have $84 \%$ of the smoking population which may increase to $88 \%$ by 2025 . It is well established that tobacco consumers have more chances of dying a premature death of several tobacco attributable diseases like cancer, heart diseases, respiratory problems and COVID-19, which may lead to income deprivation along with health care cost (Pinto \& Uga, 2010; Vardavas \& Nikitara, 2020).

Like other developing world, South Asian countries also face high economic cost due to tobacco attributable diseases. Lower Human Development Index (HDI) scores and high smoking prevalence have resulted in multitude of vicious circles of different health and social issues. More than 160,000 people in Pakistan and almost 161,200 smokers lost their lives in Bangladesh on annual basis due to smoking induced causes. Monetary value of economic cost reaches to 143 billion rupees in Pakistan while in Bangladesh the cost is as much as 50.9 billion takkas against 24.8 billion takkas of benefit in the form of wages and revenue (World Health Organization, 2007). Similarly, India, Sri Lanka, Nepal and Bhutan also face enormous health cost both in monetary and human lives forms. Tobacco attributable death toll has reached to $699,504,9,932,14,456$ and 156 people on annual basis in India, Sri Lanka, Nepal and Bhutan respectively whereas, the economic cost is 22.4 billion USD, 99,965 million Sri Lanka Rupees, 22,942 million Nepalese rupees and 1,215 million ngultrums (The Tobacco Atlas, 2018).

Considering the expansionary scenario of tobacco prevalence in developing countries, more than 190 member states of the World Health Organization (WHO) proposed a universal treaty, Framework Convention on Tobacco Control (FCTC) for the tobacco control at the $52^{\text {nd }}$ session of World Health Assembly in 1999. After discussion for four years on different aspects of the treaty it was ratified during $56^{\text {th }}$ session of the World Health Assembly in 2003. In order to make the tobacco control policies more effective, the WHO-FCTC provided detailed guidelines for tobacco control legislation, which may overcome the pitfalls of sporadic and isolated measures by a member country. Tax policy covered in article 6 requires tax rates to be 75 percent of the retail price of tobacco products while article 8 provides details of smoke free policy. Warning labels covered in article 11 require that at-least 50 percent of the front and back area of tobacco packs be bearing warning label about health consequences of tobacco use. Similarly, article 13 guides on banning direct and indirect tobacco advertising while article 14 helps in formulating cessation support programs 
(Gravely et al., 2017). WHO-FCTC has helped the countries to converge in adopting tobacco control laws in response to global tobacco epidemic by creating international standards to control and regulate different policy aspects (Riquinho \& Hennington, 2012). It is obligatory that member nations should align their tobacco control laws with articles of the treaty to effectively control the tobacco epidemic. Although South Asian countries have ratified the protocols of the treaty but have adopted different approaches to address the tobacco control issue. The difference in compliance, timing of tobacco control policy formulation and implementation causes variations in the strength of policies and decline in smoking prevalence. The current work is aimed to check the adherence of tobacco control laws with the WHO-FCTC guidelines, compare the strength of national laws for tobacco control, analyze and compare the changes in smoking prevalence in post FCTC scenario in South Asian countries. The study hypothesized that higher compliance/adherence with the guidelines of the WHO-FCTC is associated with decline in smoking prevalence. Rest of the paper is organized as theoretical background in section two. Data and methodology are given in section three, section four describes results. Discussion is presented in section five while section six concludes the work by putting forward some useful recommendations for legislators and policy makers for better compliance and effective control of tobacco prevalence in the region.

\section{Theoretical Background}

Economic models reflecting habitual behavior are based on two key assumptions. One takes tastes as of endogenous nature while other views tastes and preferences as given or exogenous and constant over the life cycle (Chaloupka, 1991). Endogenous tastes models indicate that current behavior is based on the past behavior whereas, model of the constant and given tastes utilize the framework of household production. Additionally, some models treat the addicts as myopic who take no account of future consequences of the consumption of addictive goods. Apart from myopic models another strands of models called rational models assume that addict acts rationally and fully aware of the future consequences of consuming addictive goods. We assume that laws and regulations change smoking behavior and apply correlation analysis to study the effect of increasing compliance scores and variations in smoking prevalence rates.

At any given time, the utility of individual is assumed to be a function of three factors

$U_{(t)}=u\left(H_{(t)}, R_{(t)} Z_{(t)}\right)$ such that $U_{i}>0, U_{i i}<0, i=H, R, Z$

Where,

$\mathrm{H}_{(\mathrm{t})}$ is health status of individual at time $\mathrm{t}$ 
$\mathrm{R}_{(\mathrm{t})}$ is physiological and psychological relaxtion due to addictive goods consumption

$Z_{(t)}$ is vector of all other consumption goods

Production functions of health, relaxation and other goods are as follows

$$
\begin{aligned}
& H_{(t)}=H[M(t), A(t)] \text { suchthat } H_{M}>0, H_{M M}<0, H_{A}<0, H_{A A}>0 \\
& R(t)=R[C(t), A(t)] \text { suchthat } R_{C}>0, R_{C C}<0, R_{A}<0, R_{A A}<0 \text { and } R_{C A}>0 \\
& Z(t)=Z[X(t)] \text { with } Z_{X}>0, Z_{X X}<0
\end{aligned}
$$

A derived instantaneous utility function can be obtained as

$$
U(t)=U[C(t), A(t), Y(t)]
$$

where $c(t)$ is cigarettes, $A(t)$ is addictive stock and $Y(t)$ are inputs int $X(t)$

Consumers choose different goods in their utility functions depending on the prices, income and preferences. They aim to maximize their utility in the given constrained situation. There are some addictive goods which have harmful effects on the overall well-being of individuals and families. However, all consumers have not the same goods in their utility function. Some consume one set of goods while others derive their utility from other set of commodities. We can give the utility function of a typical consumer as follows

$$
U=U\left[D . X_{1}, X_{2}, X_{3}, \ldots \ldots . X_{n} ; W\{S\}\right]
$$

Where,

$\chi_{1}$ is smoking good

$\chi_{2}, X_{3}, \ldots \ldots . X_{n}$ are all other goods

W\{S\} are qualitative factors encouraging or discouraging smoking

$D=1$ if individual is actual smoker, $D=0$ otherwise

We assume that all other goods are necessary for sustenance and always present in the consumption set of all individuals while smoking decisions are not taken by all. Those who choose smoking is reflected by D. The demand function for smoking is given as below,

$$
X=D \frac{\partial c}{\partial p 1}
$$




$$
X=-D \frac{\frac{\partial v}{\partial p 1}}{\left(\frac{\partial v}{\partial m}\right)}
$$

$\mathrm{c}\left(\mathrm{p}_{1}, \mathrm{u}\right)$ is the cost and $\mathrm{v}(\mathrm{p} 1, \mathrm{~m})$ is the indirect utility corresponding to utility function in equation (1), $p_{1}=p / D$ where $p$ is price of smoking good, $m$ is total expenditure. If $\mathrm{D}$ is always equal to 1 , everyone is smoker and $\mathrm{D}=0$ means a standard corner solution.

Addictive commodities' consumption depends on consumption in past but here we assume inter-temporal separability, then current consumption decisions are based on the indirect utility function

$$
v(p, m)=\operatorname{Max}\left[U\left(D . X_{1}, X_{2}, X_{3}, \ldots \ldots . X_{n} ; W\{S\}\right) \mid p^{\prime} x=m\right]
$$

Where p' is vector of prices.

Consumer decides to participate in smoking if the utility at positive smoking level is more than zero smoking level.

$$
\begin{aligned}
& D=1 \quad \text { if€> } 0 \\
& =0 \text { otherwise } \\
& €=\left[v(.)-v^{*}(.)\right]+\left[W(S)-W^{*}(S)\right]
\end{aligned}
$$

Participation equation has two components i.e difference of utility levels at zero $\&$ positive smoking and net qualitative factors. Difference in utility levels depends on the price level and individual income. If prices are high and income is low, there can be decrease in utility and less participation. However, it is the combined effect of both, difference in utility levels at zero and positive smoking and qualitative effects which decides the participation and smoking prevalence rates. However, once smoking is initiated, the addictive and harmful nature of smoking good causes the long-term utility to decline. With increasing the stock of smoking the desire for further smoking rises which causes stress and other health related issues. These factors have adverse effects on the overall well-being of individuals, families and societies. Institutional economists claim that human behavior is the result of institutions and institutional qualities.

Different studies using myopic and rational addiction models predict inverse relation of smoking goods with own price. Other institutional interventions like banning the sale to minors, open cigarettes, advertisement can delay the initiation 
and stock of addiction by limiting access, affordability and making it an anomalous behavior. Other measures change the qualitative aspects to decrease the participation rate of new entrants and encourage with-drawl of current smokers. Taxation of smoking goods changes the relative prices to reduce the participation and encourage with-drawl by creating a disutility. Similarly, ban on advertisement can help in considering it to be an anomalous behavior and ban on smoking in public places will make smoking against the social taboos and decrease the qualitative effects associated with smoking. In the same way health warning can increase the psychological cost and negatively affecting the qualitative effects of smoking. Although, these policies play their individual role in effective way but synergistically applying them can reinforce the effects of one another to control smoking prevalence rates as well as per capita smoking consumption. Participation equation will be

$$
\partial € / \partial \operatorname{Int}=\frac{\partial}{\partial \operatorname{Int}}\left[\mathrm{v}(.)-\mathrm{v}^{*}(.)\right]+\left[\mathrm{W}(\mathrm{S})-\mathrm{W}^{*}(\mathrm{~S})\right]<0 \text { and hence } \mathrm{D}=0
$$

Where

$€$ is participation and Int stands for institutional intervention

The comprehensive interventions will lead to less participation at given time.

\section{Data and Methodology}

We selected South Asian countries for the study due to high prevalence rates of tobacco consumption. Due to large market, these countries are the prime target of tobacco industry. Along with high tobacco prevalence rates, these countries are the second main suppliers after China for tobacco products inputs. Due to low-cost labor, tobacco business has been lucrative for tobacco industry which poses great risk to public health. Although these countries have variation in their population size but regarding tobacco control aspects like tobacco epidemic, harms, obstacles and required actions for tobacco control, these countries reflect huge similarities (Mackay, Ritthiphakde, \& Reddy, 2013). To answer our research questions and test our hypothesis we employed positivist approach and correlation analysis of compliance score and smoking prevalence rates. For this purpose, we collected the required data from various secondary sources like the official Gazette books of the South Asian countries, World Health Organization (WHO) report on global tobacco epidemic, 2015, WHO report on global tobacco epidemic, 2017, WHO global report on trends in tobacco smoking, 2000-2025), The website (tobacco control laws) of the campaign for Tobacco-Free Kids, Our World in Data (Roser \& Ritchie, 2018), population pyramid. net and the World Bank. Unofficial translation of the tobacco control ordinances and regulatory orders, tobacco control policy fact sheets of the South Asian countries were downloaded from the site (www.tobaccocontrollaws) developed by "Campaign for 
Tobacco-Free Kids". We checked the summary fact-sheets of tobacco control laws in different countries and estimated their compliance score with the FCTC guidelines. The protocols of the FCTC were taken as standard criteria for comparison of the tobacco control laws as all these countries have ratified the WHO-FCTC treaty. Also, the protocols provided by the FCTC have played an important role in helping domestic courts in the interpretation of tobacco control laws (Muggli et al., 2014). To fulfill the objectives of the study, it was investigated whether the specific country has followed the criteria or not. We checked in the official Gazette books of respective country whether the law exists for a specific domain or not. Tobacco control laws passed in South Asian countries are given in annexure 1. After establishing the existence of a national law, we compared these laws with the guidelines of the FCTC for compliance. The existence of law and following the articles' guidelines of the WHO-FCTC for the specific domain was termed as compliance of the law represented by " 1 " whereas, non-existence and non-compliance was represented by " 0 " for the specific domains like smoke-free; advertisement, promotion \& sponsorship; and packaging \& labeling laws for tobacco control. After identifying for the existence and compliance of tobacco control laws, we compared and ranked the countries in terms of compliance. We checked compliance of smoke-free laws by whether eight entities including "health care facilities, primary \& secondary schools, universities, government facilities, private offices, public transport, restaurants and bars \& pubs" are ensured to be smoke-free or not. Major entities including "domestic television \& radio, domestic magazines and newspapers, outdoor advertising, point of sale advertising, retail product display, internet advertising, free distribution, promotional discounts, non-tobacco products or services with tobacco brand names, tobacco products with non-tobacco brand names, paid placement in media, financial sponsorship including Corporate Social Responsibility (CSR) and publicity of sponsorship" in the domain of advertisement, promotion and sponsorship policy. Law about packaging and labeling consists of seven entities including text warnings describing health impacts, warning in pictorial or graphical form, $50 \%$ of principal display area (front and back), requirement for rotation of warnings, requirement of warnings to be in the principal language of the country, requirement for ban on the misleading packaging \& labeling and health warning on smokeless tobacco products.

\subsection{Construction of policy index}

Different tobacco control policies have variations in their effects in reducing tobacco prevalence. Some countries performed extra-ordinary in one policy but lagged in others and it was difficult to rank countries on the basis of heterogeneity and differential effects of different policies. Therefore, we constructed a combined index to rank the countries. To rank the countries for compliance we constructed policy 
specific and overall indices. We used weight-age of $61 \%$ for tax, $22 \%$ for marketing ban, $4 \%$ for health warning and $7 \%$ for smoke-free law on the basis of their importance in smoking reduction estimated by Levy, Benjakul, Ross, and Ritthiphakdee (2008). Tax compliance index was constructed by dividing the proportion of tax in retail price by the FCTC proposed tax rate of $70 \%$ and multiplied by $61 \%$. Similarly, ban on advertisement, promotion and sponsorship compliance ratio was multiplied by $22 \%$ whereas, health warning \& labeling and smoke free laws' compliance ratios were multiplied by $4 \%$ and $7 \%$ respectively. To get the overall index we added all the compliance indices.

\subsubsection{Construction of tax index}

Tax index is given by the equation

$$
\text { Taxindex }_{i}=\frac{\text { Taxprop }_{i}}{\text { Pr } \text { oposedtax }_{\text {Tos }}} \times 0.61
$$

Taxindex $_{i}$ stands for tax index in country ${ }_{i}$

Taxprop $_{i}$ stands for tax proportion in final retail price in country $\mathrm{i}$

Proposedtax stands for proposed tax rates in final retail price by the WHO-FCTC guidelines

\subsubsection{Construction of marketing ban index}

The index for marketing ban is given by the following equation

$$
\text { Marketingbanindex }_{i}=\text { Compratio }_{i} \times 0.22
$$

Marketingbanindex ${ }_{i}$ stands for index score for ban on tobacco advertisement, promotion and sponsorship in each country

Compratio stands for compliance ratio with the law on marketing ban in each country

\subsubsection{Construction of packaging and labeling index}

Labeling and health warning index is given by

$$
\text { labelingindex }_{i}=\text { Compratio }_{i} \times 0.04
$$

Labelingindex ${ }_{i}$ stands for index score on labeling and health warning index in each country

Compratio $_{i}$ stands for compliance ratio with labeling and packaging law in country $\mathrm{i}$ 


\subsubsection{Construction of index for smoke free laws}

Index for compliance with smoke free laws is given by equation smokefreeindex $_{i}=$ Compratio $_{i} \times 0.07$

smokefreeindex $_{i}$ stands for index on smoke free laws in country $i$

Compratio $_{i}$ stands for compliance ratio with smoke-free laws in country i

\subsubsection{Construction of overall index for tobacco control laws}

The overall compliance index was constructed by adding the policy specific indices and given by the following equation

complianceindex $x_{i}=$ taxindex $_{i}+$ marketingbanindex $_{i}+$ labelingindex $_{i}+$ smokefreeindex $_{i}$

We carried out correlation analysis to check the degree of association between different tobacco control policies and decline in smoking prevalence. Before the correlation we calculated the compliance index for each policy and then aggregated them to one whole index. The correlation was carried for decline in smoking prevalence as defined in the above section, marketing ban index, packaging and labeling law index, smoke-free law index, price of cigarette packs in dollar and overall compliance index score.

\subsection{Measuring the effect of tobacco control laws on smoking control}

To know about the impact of tobacco control measures taken after the WHOFCTC treaty in the South Asian countries we estimated the changes in smoking prevalence between 2005 and 2018. The change in smoking prevalence is determined by the following equation.

$\Delta S p_{i}=\frac{S P 18-S P 05_{i}}{S P 05 i} \stackrel{\underline{\underline{i}}}{\Delta} \times 100$

$\Delta$ Sp Represents change in the smoking prevalence between 2005 and 2018 for respective country

SP18 ${ }_{i}$ Represents smoking prevalence in 2018 for respective country

SP05 Represents smoking prevalence in 2005 for respective country

\section{Results}

This section reports the findings of this research regarding tobacco control laws, their compliance status with the WHO-FCTC guidelines and their impact on smoking 
prevalence rates.

\subsection{Comparative analysis}

We present the comparison of compliance with the articles of WHO-FCTC of national laws governing tobacco control in South Asian countries.

\subsubsection{Compliance status for smoke free laws}

Findings of the study revealed that South Asian countries have $100 \%$ smoke-free status and compliance with the proposed guidelines for the categories of "government facilities, hospitals, residential health care facilities, non-residential health care facilities, childcare facilities, primary and secondary schools, universities/vocational facilities, shops, cultural facilities and indoor stadiums but Pakistan' compliance is none for all these mentioned places except all public transport whereas, Bangladesh lags in compliance for cultural facilities and indoor stadiums and Bhutan for indoor stadiums. Although Pakistan, Nepal and Bhutan have laws that restaurants to be $100 \%$ smoke-free but these laws are hardly observed and smoking prevails in every restaurant in small towns and specifically in informal sectors. The study found no compliance with the FCTC guidelines for all indoor public and work places whereas, for public transport the situation is mix one. On the overall basis, Nepal and Bhutan have the highest compliance ratios of 18/24 while Pakistan complies with 5/22 for smoke free laws among the South Asian countries. Details are presented in Table 1.

\subsubsection{Compliance status for ban policy on tobacco advertisement}

Advertisement is an important tool of competition in the highly concentrated industry where, firms tend to increase sales with advertising and other marketing techniques but not by price. This study found that legislation covered domestic media like television, radio, newspapers, magazines and other print media in south Asian countries. Although ban on domestic media is comprehensive and adheres with the FCTC guidelines but the case for international media is not. We found that countries like India lags in compliance with internet tobacco product sale, product display, toys and candy resemblance, unpaid depiction in media and misleading promotion. Only Nepal complies with the FCTC in the mode of sponsorship and publicity of financial support of tobacco industry. Regarding direct personal targeting, India and Nepal have high compliance ratios while in control of misleading promotion Nepal and Bhutan complies with the FCTC guidelines. The study further revealed that Nepal has the most comprehensive advertisement control policy in the region achieving maximum adherence score of 26 whereas; Pakistan has the least adherence score of 10. Results are presented in the Table 2 . 


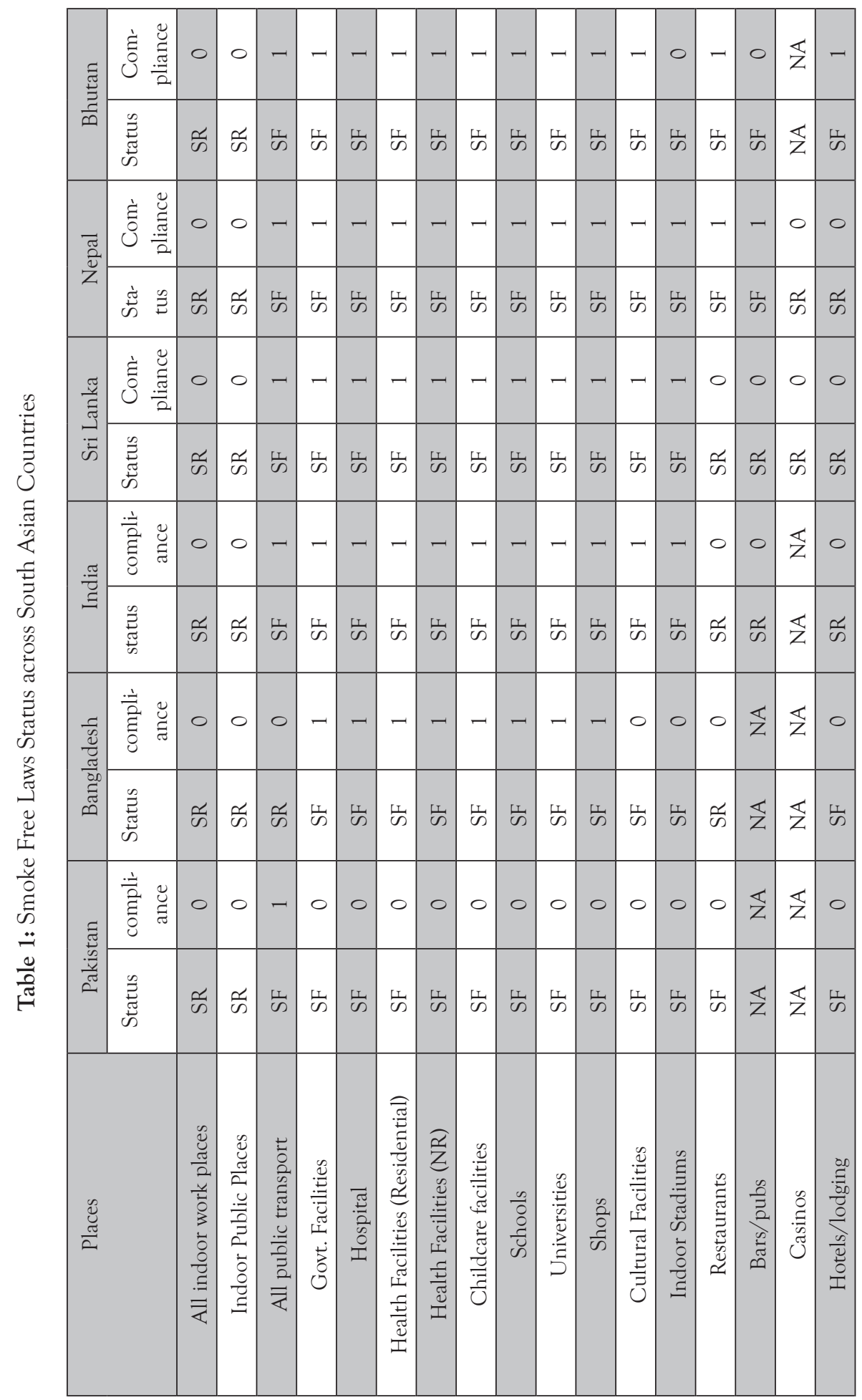




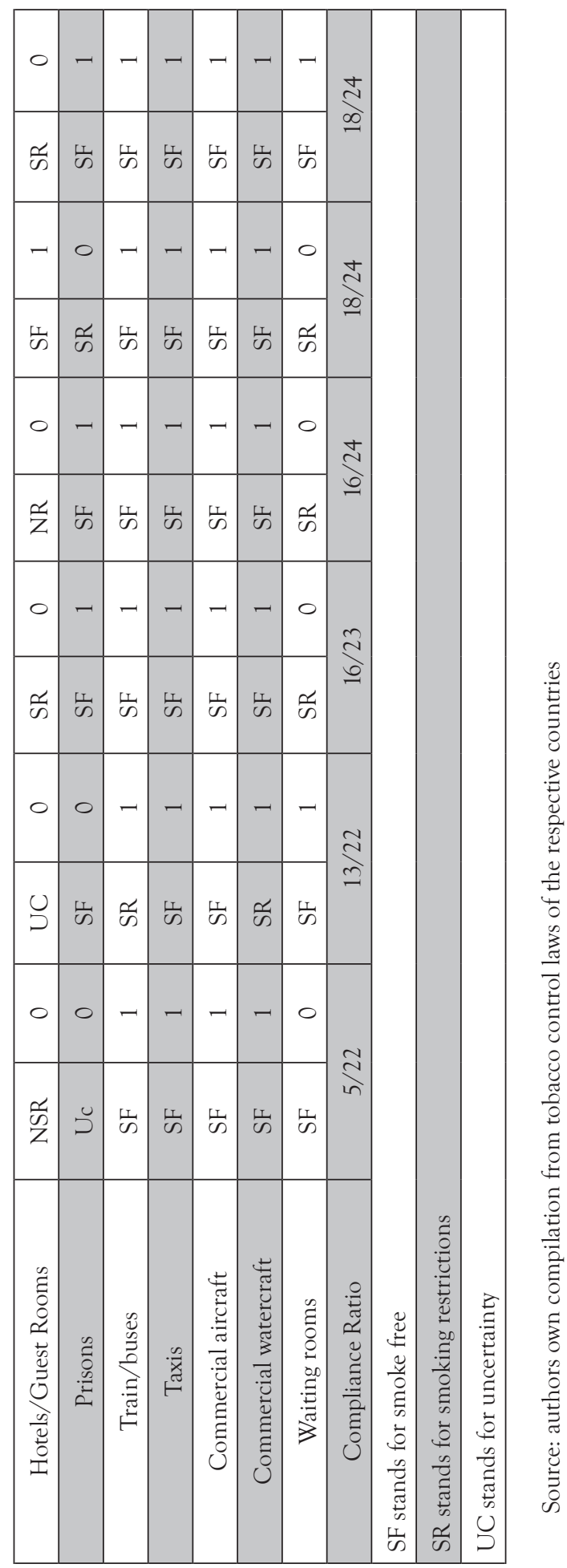




\begin{tabular}{|c|c|c|c|c|c|c|c|c|c|c|c|c|c|c|c|c|c|}
\hline Е్తే & 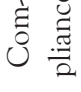 & - & -1 & - & * & ${ }^{*} 0$ & - & * & - & * & * & $\stackrel{*}{-}$ & - & - & - & - & $\stackrel{*}{-}$ \\
\hline$\overline{\oplus 0}$ & 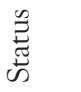 & - & - & - & ${ }^{*}$ & ${ }^{*} 0$ & - & $\stackrel{*}{\sim}$ & - & $\stackrel{*}{\sim}$ & $\stackrel{*}{\sim}$ & $\stackrel{*}{-}$ & - & - & - & $\neg$ & $\stackrel{*}{-}$ \\
\hline$\widetilde{\widetilde{a}}$ & $\begin{array}{l}\dot{\Xi} \\
\dot{\Xi} \\
\dot{\Xi}\end{array}$ & $\neg$ & - & - & $\stackrel{*}{\circ}$ & $\stackrel{*}{\circ}$ & - & -1 & - & - & - & - & - & - & - & - & - \\
\hline 2 & 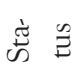 & - & - & - & ${ }^{*}$ & ${ }^{*}$ & - & - & - & - & - & - & - & - & - & $\neg$ & - \\
\hline$\frac{\widetilde{\widetilde{J}}}{\text { క్ }}$ & 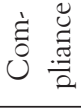 & - & - & - & ${ }^{*}$ & $\stackrel{*}{\circ}$ & - & - & - & - & 0 & - & - & 0 & - & - & - \\
\hline के & 总 & - & - & - & ${ }^{*}$ & ${ }_{0}^{*}$ & - & - & - & - & 0 & $\neg$ & - & 0 & - & - & - \\
\hline.$\simeq$ & 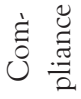 & $\neg$ & - & - & $\stackrel{*}{\circ}$ & $\stackrel{*}{\circ}$ & - & 0 & - & - & $\stackrel{*}{\circ}$ & - & - & - & - & - & - \\
\hline$=$ & 芶 & $\neg$ & -1 & - & $\stackrel{*}{\circ}$ & $\stackrel{*}{\circ}$ & - & 0 & - & - & $\stackrel{*}{\circ}$ & - & - & $\neg$ & $\neg$ & $\neg$ & - \\
\hline$\frac{\tau}{\frac{\tilde{s}}{0}}$ & 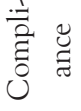 & - & - & - & $\stackrel{*}{\circ}$ & $\stackrel{*}{0}$ & - & 0 & - & - & - & - & - & $\neg$ & - & - & - \\
\hline ॠ్ & 芶 & - & - & - & $\stackrel{*}{\circ}$ & ${ }^{*}$ & - & 0 & - & - & - & - & - & - & - & $\neg$ & - \\
\hline$\approx$ & 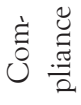 & - & - & - & * & * & 0 & 0 & $\stackrel{*}{\circ}$ & * & - & 0 & 0 & 0 & 0 & - & - \\
\hline$\approx$ & 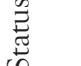 & $\neg$ & - & - & ${ }^{*}$ & * & 0 & 0 & ${ }^{*} 0$ & * & - & 0 & 0 & 0 & 0 & - & - \\
\hline 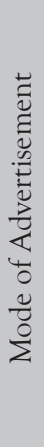 & & 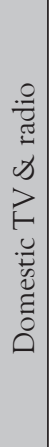 & 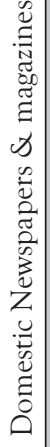 & 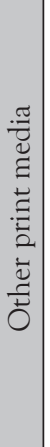 & 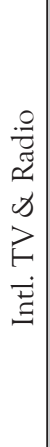 & 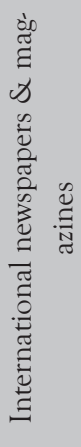 & 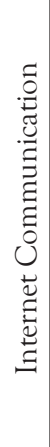 & 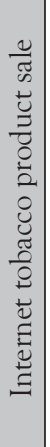 & 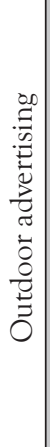 & 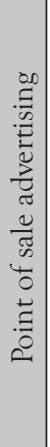 & 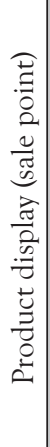 & 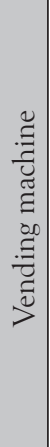 & 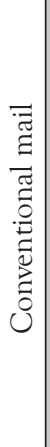 & 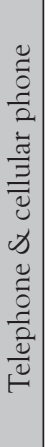 & 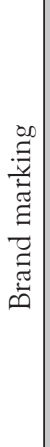 & 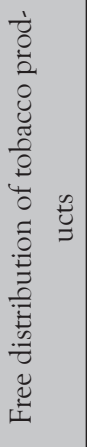 & 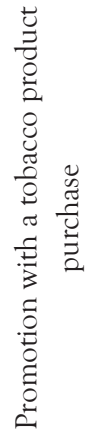 \\
\hline
\end{tabular}




\begin{tabular}{|c|c|c|c|c|c|c|c|c|c|c|c|c|c|c|c|}
\hline- & ${ }^{*}$ & - & $*^{*}$ & * & ${ }^{*} 0$ & $\stackrel{*}{-}$ & * & - & 0 & 0 & - & 2 & $\stackrel{\infty}{\sim}$ & & \\
\hline- & * & - & ${ }^{*}$ & ${ }^{*}$ & ${ }^{*}$ & $\stackrel{*}{-}$ & ${ }^{*}$ & - & ${ }^{*} 0$ & ${ }^{*}$ & - & $\curvearrowright$ & $\stackrel{\infty}{\sim}$ & & \\
\hline- & $\neg$ & - & - & $\neg$ & - & - & - & - & - & - & - & $\stackrel{\sim}{\sim}$ & $\stackrel{\infty}{\sim}$ & & \\
\hline- & - & - & - & - & - & - & - & - & - & - & - & $\stackrel{2}{\sim}$ & $\stackrel{\infty}{\sim}$ & & \\
\hline- & 0 & - & 0 & - & - & 0 & - & - & 0 & 0 & 0 & 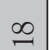 & $\stackrel{\infty}{\sim}$ & & \\
\hline- & 0 & - & 0 & - & - & 0 & - & - & ${ }^{*} 0$ & $*$ & 0 & $\stackrel{\infty}{=}$ & $\stackrel{\infty}{\sim}$ & & \\
\hline- & - & - & - & ${ }^{*}$ & ${ }^{*}$ & - & - & 0 & ${ }^{*}$ & ${ }^{*}$ & ${ }^{*}$ & $\simeq$ & $\stackrel{\infty}{\sim}$ & $\begin{array}{l}\cup \\
\cup \\
\cup\end{array}$ & $\begin{array}{l}\stackrel{\widetilde{g}}{0} \\
\stackrel{2}{2}\end{array}$ \\
\hline- & - & - & - & $\stackrel{*}{\circ}$ & $\stackrel{*}{0}$ & $\neg$ & - & $\stackrel{*}{\circ}$ & $\stackrel{*}{\circ}$ & $\stackrel{*}{0}$ & ${ }^{*}$ & $\stackrel{\infty}{=}$ & $\stackrel{\infty}{\sim}$ & $\begin{array}{l}\bar{u} \\
\tilde{\Xi} \\
\underline{\Xi}\end{array}$ & 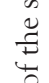 \\
\hline- & 0 & $\stackrel{*}{\circ}$ & 0 & $\neg$ & - & $\neg$ & $\neg$ & $\neg$ & $\stackrel{*}{0}$ & $\stackrel{*}{\circ}$ & $\stackrel{*}{\circ}$ & 2 & $\stackrel{\infty}{\sim}$ & 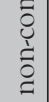 & $\begin{array}{l}\tilde{\Xi} \\
0 \\
0 \\
\mathscr{\Xi}\end{array}$ \\
\hline- & $\stackrel{*}{\circ}$ & $\stackrel{*}{\circ}$ & 0 & - & $\neg$ & $\neg$ & $\neg$ & - & $\stackrel{*}{\circ}$ & $\stackrel{*}{0}$ & $\stackrel{*}{\circ}$ & 2 & $\stackrel{\infty}{\sim}$ & $\begin{array}{l}\tilde{\sigma} \\
\tilde{U} \\
\tilde{U} \\
\text { un }\end{array}$ & 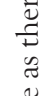 \\
\hline * & 0 & $\stackrel{*}{0}$ & 0 & - & - & 0 & - & - & ${ }^{*}$ & $\stackrel{*}{\circ}$ & ${ }^{*}$ & 으 & $\stackrel{\infty}{\sim}$ & $\begin{array}{l}I \\
\vdots \\
\vdots \\
0 \\
0\end{array}$ & 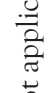 \\
\hline * & 0 & $*^{*}$ & 0 & $\neg$ & $\neg$ & 0 & - & 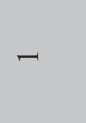 & $*^{*}$ & ${ }^{*}$ & $\stackrel{*}{0}^{\circ}$ & 으 & $\stackrel{\infty}{\sim}$ & 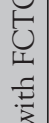 & $\begin{array}{l}\underbrace{0}_{0} \\
* \\
E\end{array}$ \\
\hline 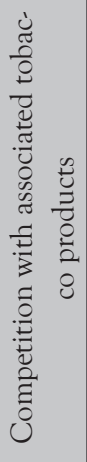 & 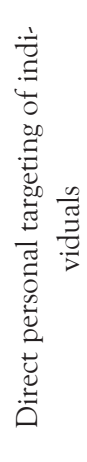 & 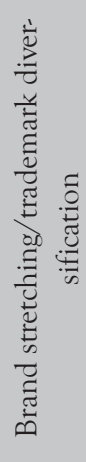 & 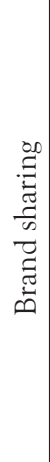 & 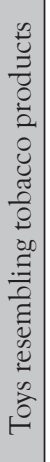 & 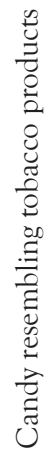 & 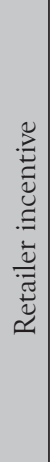 & 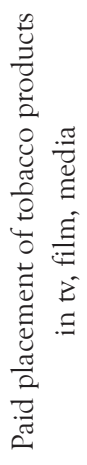 & 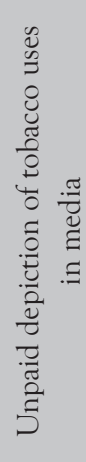 & $\begin{array}{l}0 \\
0 \\
0 \\
0 \\
u \\
0 \\
0 \\
0 \\
0 \\
0 \\
0 \\
0 \\
0 \\
0 \\
\text { के }\end{array}$ & 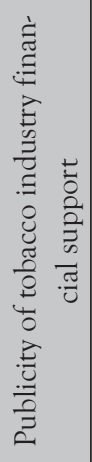 & 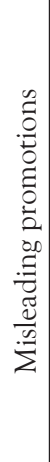 & 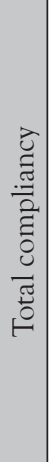 & 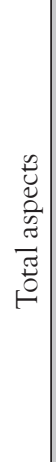 & 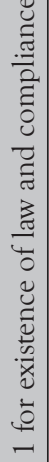 & 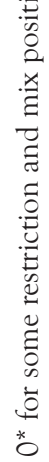 \\
\hline
\end{tabular}




\subsubsection{Compliance status for packaging and labeling policy}

Attractive packaging and labeling play an important role in reducing the effect of advertisement ban in marketing of tobacco products and attracting consumer (Wakefield, Morley, Horan \& Cummings, 2002). We found that all the South Asian countries have followed the WHO-FCTC guidelines about warning on unit packaging, outside packaging and the adoption of principal language (understanding the message). However, we found that none of these countries comply with the display of figure of emission and plain packaging guidelines. Findings show that Pakistan and Bangladesh lag in compliance with prohibited misleading packaging. Along with misleading packaging, Pakistan also lags in number of health warning regulation, where the law covers only three aspects in total of nine. Like smoke-free and marketing ban policies, Nepal has highest compliance for packaging and labeling policy also in South Asian region, with a total compliance of 7 among the countries where tobacco business is legal. Compliance scores are given in Table 3.

\subsubsection{Compliance status for taxing and price policy}

Article 6 of the WHO-FCTC covers the price and taxation measures. The most impactful way to reduce tobacco consumption is to tax tobacco products. The proposed excise tax rate is $70 \%$ of the final retail price (Campaign for Tobacco-Free Kids). Unfortunately, none of the country in South Asian region has followed the taxation policy aligned with the WHO-FCTC guidelines. We found complex tax structure and loopholes for evasion of tax in South Asian countries. Findings of the study show that Bangladesh has the highest tax share in the final price of tobacco products. The share of excise tax is $62 \%$ of the final retail price and total tax share reaches 75.6 percent followed by Sri Lanka with excise share of $51 \%$. On the other hand, Nepal and India have the least shares of 15 and 26 percent for excise tax but in total tax share India leads Pakistan. Taxing tobacco products are meant to increase tobacco prices and Sri Lanka leads the region in terms of tobacco prices followed by India. In contrast, Pakistan has the lowest prices for cigarettes in the region. Results of the taxation and prices are presented in Table 4.

\subsubsection{Compliance status for weighted compliance index}

Ranking countries for compliance with tobacco control laws shows that for taxation findings reveal that Bangladesh has the highest score of 0.540 in the maximum possible of 0.61 followed by Sri Lanka with 0.444 while Nepal and India have the lowest compliance with tobacco excise taxation. Regarding policy of marketing ban (advertisement, promotion and sponsorship) study found that Nepal followed by Bangladesh has the highest compliance score of 0.204 and 0.149 in maximum 


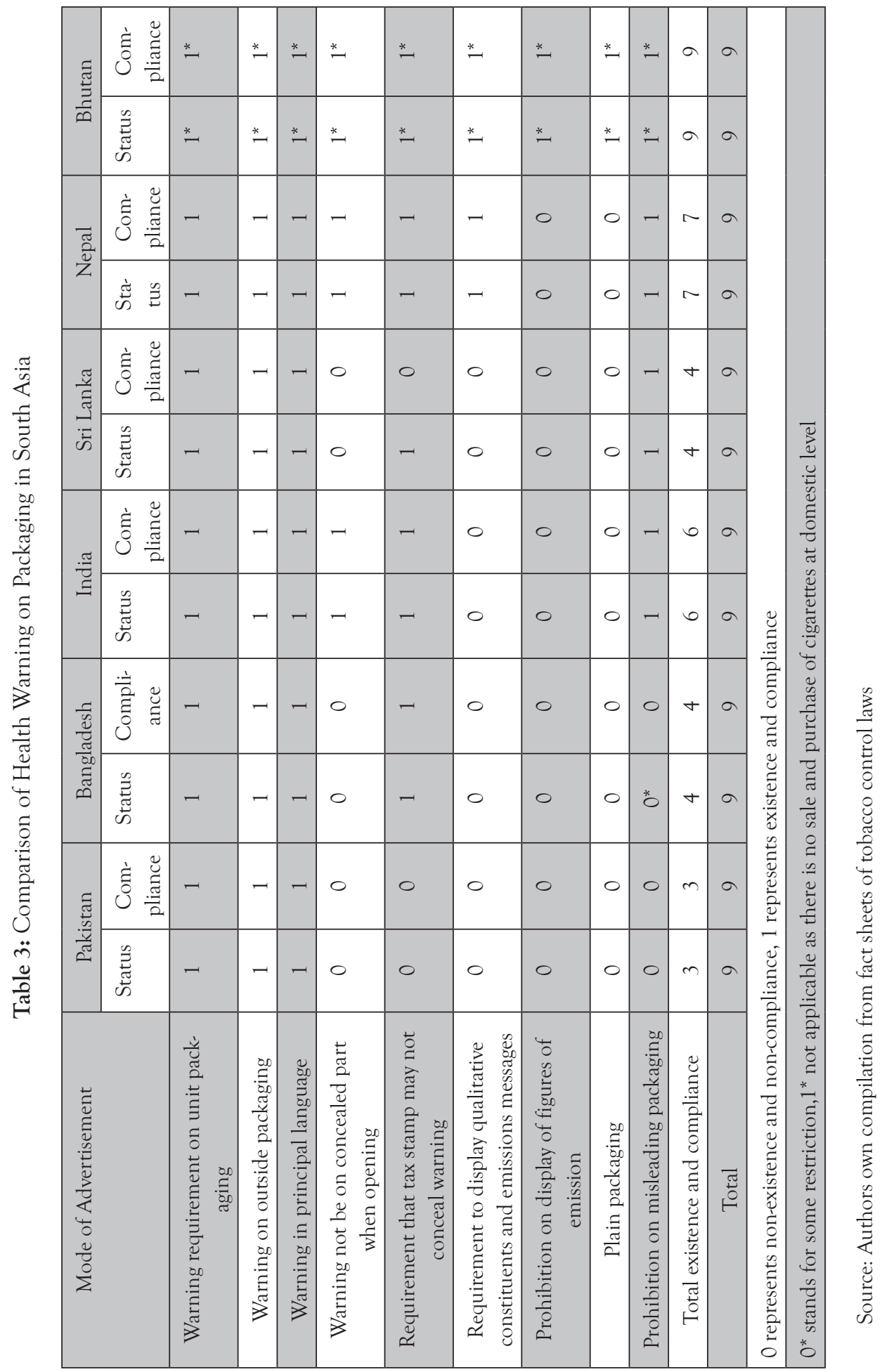


Table 4: Tobacco Taxation and Prices across South Asian Countries

\begin{tabular}{|c|c|c|c|c|}
\hline Country Name & $\begin{array}{c}\text { Excise tax (\%age } \\
\text { of retail price) }\end{array}$ & $\begin{array}{c}\text { Total tax (\%age } \\
\text { of retail price) }\end{array}$ & $\begin{array}{c}\text { Price (domestic } \\
\text { currency) }\end{array}$ & Price (USD) \\
\hline Pakistan & 46 & 60.7 & 67 PKR & 0.64 \\
\hline Bangladesh & 62 & 75.6 & $1000 \mathrm{BDT}$ & 1.28 \\
\hline India & 26 & 66.1 & $158 \mathrm{INR}$ & 2.36 \\
\hline Nepal & 15 & 46.6 & $180 \mathrm{NPR}$ & 1.68 \\
\hline Sri Lanka & 51 & 73.5 & $1000 \mathrm{LKR}$ & 6.86 \\
\hline
\end{tabular}

Source: WHO, 2015, 2017

possible of 0.22 whereas, Pakistan lags in compliance score. Similar is the case for other two policies i.e., smoke-free and packaging \& labeling laws. On the overall basis, Bangladesh leads the South Asian countries followed by Sri Lanka having index scores of 0.748 and 0.650 respectively whereas, Nepal despite of leading compliance in three polices, lags in overall index score. Summary of the policy specific and overall compliance index scores are presented in Table 5.

\subsection{Smoking decline in post-FCTC scenario}

Table 5: Compliance Index Scores

\begin{tabular}{|c|c|c|c|c|c|}
\hline \multirow{2}{*}{ Country } & \multicolumn{5}{|c|}{ Policy Index score } \\
\cline { 2 - 6 } & Taxation & Marketing ban & Smoke free & Labeling \& Packaging & Overall \\
\hline Pakistan & 0.401 & 0.078 & 0.012 & 0.013 & 0.504 \\
\hline Bangladesh & 0.540 & 0.149 & 0.041 & 0.018 & 0.748 \\
\hline India & 0.226 & 0.134 & 0.049 & 0.027 & 0.456 \\
\hline Sri Lanka & 0.444 & 0.141 & 0.047 & 0.018 & 0.650 \\
\hline Nepal & 0.131 & 0.204 & 0.052 & 0.031 & 0.388 \\
\hline
\end{tabular}

Source: Authors own calculation based on weights of sim-smoke model

Providing boost to health awareness we see declining trends in smoking prevalence rates in post FCTC scenario across the globe. Similarly, we found a continuous declining trend in the overall smoking prevalence in all the South Asian countries. Among these countries India, followed by Nepal achieved the highest decline in smoking prevalence despite their lower overall compliance index scores. Nepal had the highest smoking prevalence rates in 2005 followed by Bangladesh and Pakistan whereas, Sri Lanka had the lowest rate in the region but the heterogeneous effects of 
different control policies resulted in mixed achievements to change smoking prevalence rates till 2018. The highest decline was achieved by India followed by Nepal and Bangladesh with percentage declines of $34.68,26.39$ and 18.79 percent respectively whereas, the lowest decline in the smoking prevalence was found in Sri Lanka with 9.86 percent. We present changes in smoking prevalence rates over time in Table 6 .

\subsection{Correlation of tobacco control policies and smoking prevalence}

Table 6: Smoking Prevalence and Changes in Smoking Prevalence Over time

\begin{tabular}{|c|c|c|c|c|}
\hline \multirow{2}{*}{ Country Name } & \multicolumn{3}{|c|}{ Smoking rates Year wise } & \%age Change in smoking rates \\
& 2005 & 2010 & 2018 & Between 2005-2015 \\
\hline Pakistan & 22.7 & 21.3 & 19.8 & -12.78 \\
\hline Bangladesh & 28.2 & 25.3 & 22.9 & -18.79 \\
\hline India & 17.3 & 14.3 & 11.3 & -34.68 \\
\hline Sri Lanka & 15.2 & 14 & 13.7 & -9.86 \\
\hline Nepal & 32.2 & 27.1 & 23.7 & -26.39 \\
\hline
\end{tabular}

Source: WHO, 2015, 2018

Correlation analysis of different tobacco control policies and decline rate in smoking prevalence show that all the policies are almost high and positively correlated with decline in smoking prevalence. Association of different tobacco control policies and decline in smoking prevalence can be seen in column 2 of table 7. All these results validate the theory but the overall compliance index has negative and moderate association with the decline in smoking prevalence. The highest association was observed for packaging and labeling laws followed by smoke-free law and prices in dollars. Correlation of different policy interventions and decline in smoking prevalence is shown in table 7 .

Table 7: Correlation of Tobacco Control Policies and Decline in Smoking Prevalence

\begin{tabular}{|c|c|c|c|c|c|c|}
\hline Variables & Decline & $\begin{array}{c}\text { Marketing } \\
\text { ban }\end{array}$ & $\begin{array}{c}\text { Smoke free } \\
\text { laws }\end{array}$ & $\begin{array}{c}\text { Packaging } \\
\text { and label- } \\
\text { ing }\end{array}$ & Price & $\begin{array}{c}\text { Compli- } \\
\text { ance index }\end{array}$ \\
\hline Decline & 1.00 & & & & & \\
\hline $\begin{array}{c}\text { Marketing } \\
\text { ban }\end{array}$ & 0.605 & 1.00 & & & & \\
\hline
\end{tabular}




\begin{tabular}{|c|c|c|c|c|c|c|}
\hline $\begin{array}{c}\text { Smoke-free } \\
\text { law }\end{array}$ & 0.693 & 0.844 & 1.00 & & & \\
\hline $\begin{array}{c}\text { Packaging } \\
\text { \& Labeling }\end{array}$ & 0.927 & 0.807 & 0.779 & 1.00 & & \\
\hline Price & 0.644 & 0.8601 & 0.5952 & 0.8700 & 1.00 & 1.00 \\
\hline $\begin{array}{c}\text { Compli- } \\
\text { ance index }\end{array}$ & -0.565 & -0.192 & -0.063 & -0.625 & -0.6382 & \\
\hline
\end{tabular}

\subsection{Correlation of price and compliance}

Taxing of tobacco occupy significant place in tobacco control but tax is not an end in itself. It is meant to increase the price of tobacco products. The correlation of cigarettes prices with compliance score of tobacco control laws indicates that unlike developed world, compliance index score is negatively associated with prices of cigarettes in case of South Asian countries. Correlation of price and compliance index score is shown in the Table 8 , where the one enclosed in parenthesis is the case for South Asian countries.

Table 8: Comparative Analysis of Correlation between Price and Compliance Index

\begin{tabular}{|l|l|l|}
\hline Variables & Price & Compliance index score \\
\hline Price & 1.00 & \\
\hline Compliance index score & $0.087(-0.638)$ & 1.00 \\
\hline
\end{tabular}

\section{Discussion}

An international treaty in the form of Frame Work Convention on Tobacco Control (WHO-FCTC) has been in force for the last 15 years. The purpose of the treaty governing certain laws and regulations was to create deterrence for the people against the use of harmful tobacco which is gateway to various other illicit drugs (Egbe, Egbuchuku, Myer-Wietz \& Petersen, 2017). However, South Asian countries despite ratification of the WHO-FCTC, still have high smoking prevalence rates. Although these countries have enacted certain laws and regulations for the containment of tobacco epidemic but still many of them are off the mark in achieving the assigned target of 30 percent relative reduction in smoking prevalence. Although, findings of the study support the theory on individual policy basis like smoke-free laws, marketing ban, packaging \& labeling law and price of cigarettes. It was hypothesized that smoking prevalence would decline with increasing scores for compliance index but in case of South Asia, countries having low share of excise tax in final retail price like India and Nepal achieved significant reduction in smoking prevalence rates. For individual policies, index score and decline in smoking prevalence rates have close 
association and these findings match with theory and literature (Wasserman, Manning, Newhouse, \& Winkler, 1991) and (Keeler, Hu, Barnett \& Manning, 1993). Although WHO-FCTC' proposed tax share is 75 percent of the final retail prices to effectively tackle the smoking issue but we found lack of compliance with the proposed tax rule for South Asian countries in their tobacco tax policies. Findings show large variations in tax rates as well as prices for tobacco products. The tax increase is meant to raise the final retail prices for tobacco products but the complex tax structure of tiered and ad-valorem system diminishes the effects of taxation as smokers switched to lower tiers. In the region Pakistan, Bangladesh and Sri Lanka have highest share of excise tax in final retail prices but the prices are lowest in Pakistan and Bangladesh in international dollars. Pakistan has very complex tax system and different laws in its land as the proximities with Afghanistan border former Federally Administered Tribal Areas (FATA), Azad Jammu \& Kashmir (AJK) territory and main-land where law enforcement has high variations, further aggravates the tobacco prevalence scenario and tobacco control performance. The poor performance despite the high proportion of excise tax in the lowest prices for cigarettes in the region are in conformity with the findings of other studies (Huq, Nargis, Lkhagvasuren, Hussain \& Fong, 2018) which associate the success of tobacco control with the tax structure to control tier switching. Though taxation has been one of the most important and favorite intervention for the governments to control tobacco prevalence as well as raise revenue for different functions of the government. However, tobacco industry has been using different strategies to scare the governments of revenue losses due to the issue of illicit trade of smuggling and get introduced the tiered-tax system. The WHO-FCTC is aware of these tactics of tobacco industry and illicit trade issue has been addressed with article 15 of the framework convention on tobacco control. Illicit trade and smuggling issues have been exploited by the tobacco industry to not only undermine and oppose tobacco tax rise but also hamper packaging, advertisement, and size reduction policies (Stoklosa, 2016). Findings of the study revealed that countries having higher prices for tobacco have lower prevalence rates and the marginal decrease can be lowered for lower prevalence countries and vice versa. It clearly reflects that using the tax for increasing the prices will control the admission rates and more reduction in smoking prevalence rates in future. The tiered system along with the dynamics of the economies in the form of enhanced purchasing power on the part of consumers weakens the effectiveness of taxation. Therefore, the WHO-FCTC calls for other interventions to change the behavior of smokers. These policies have shown strong association with decline in smoking prevalence rates. The rule of law plays important role in achieving results of a policy. Regulatory enforcement shows the commitment of a country to a cause where South Asian countries lag the developed world. Comparatively, the regulatory index score is high for India as compared to Bangladesh and Pakistan who have higher compliance with the FCTC for tobacco control legislation 
(Agrast, Botero \& Ponce, 2009). Indian civil society efforts for tobacco control have compelled the government to expand the services of cessation centers for effective tobacco control and act on the article 14 of the WHO-FCTC (Kaur \& Jain, 2011). Although tobacco industry has been busy in hampering the enforcement of tobacco control policy however, tackling the rising tobacco attributable diseases' burden can be achieved through good governance, political will, commitment and investing in innovating the health promoting lifestyle (Amul \& Pang, 2017).

\section{Conclusion and Recommendations}

The study concludes that the South Asian countries have variations in achievement and compliance with the FCTC protocols for tobacco control. Public transport, hospitals, schools and universities, cultural facilities have been declared smoke-free but Pakistan and Bangladesh lags in adherence to the FCTC standards. Compliance index for smoke-free laws revealed that Nepal has the maximum score (0.052) whereas, Pakistan could achieve only (0.012). Price and compliance are inversely associated in South Asian countries and stands in contrast to the theoretical association between the two variables. Comparing laws about advertisement, promotion and sponsorship (marketing ban) uncertainty is observed regarding definition of key terms across South Asian countries. Domestic television, radio, newspaper, magazines and other print media are well covered as per the FCTC guidelines but international media is missing in the local legislation. Like smoke-free laws, Nepal leads the South Asian countries in terms of compliance index also for advertisement and promotion ban. However, like Pakistan the punishment for violation of advertisement laws are not aligned with the protocols of the FCTC. Banning attractive and appealing cigarette packs and information about adverse effect of tobacco can help in smoking reduction but packaging and labeling laws have lower adherence. On the overall basis Bangladesh has achieved the maximum compliance index score whereas, Nepal lags in overall compliance despite its lead in three policies. In terms of smoking prevalence reduction only India achieved the target of 30 percent relative reduction in smoking prevalence followed by Nepal and Bangladesh with 27 and 17 percent relative reduction.

The study recommends abolition of tiered-tax system of cigarette and policy formulation for the effects of tax on price increase. The study further recommends that price increase be adjusted for inflation and rise in income. A base price for cigarettes may ensure the brand switching and cessation demand. Subsidized cessation treatment be provided especially to youth. Some part of the tobacco tax revenues be earmarked for tobacco cessation. People should be educated against the health hazards of tobacco and guidance be given at school level about protecting children of the adverse effects of second-hand smoke at home. 
The study also recommends that packaging and labeling aspects be addressed on priority basis for the containment of tobacco prevalence. Smoking scenes in old movies on cable networks should be checked. Foreign media tobacco smoking scenes should be censored in all the countries. Tobacco industry's Corporate Social Responsibility (CSR) should be completely banned. Tobacco products be included in toxic substances list and it should be sold only by licensed vendors. Finally, a well-defined law will not work if it has poor enforcement therefore, tobacco control regulations be implemented in true spirit.

\section{References}

Adda, J., \& Lechène, V. (2001). Rational addiction and endogenous mortality: Does heterogeneity in life expectancy explain differences in smoking behaviour? University of Oxford Discussion Paper Series, Department of Economics, 77. Retrieved from https://www.ucl.ac.uk/ uctpjea/smoke.pdf

Agrast, M. D., Botero, J. C., \& Ponce, A. (2009). Rule of Law Index ${ }^{\mathrm{TM}}$ : Measuring adherence to the rule of law around the world/world justice project. Washington, D.C, 6-7.

Amul,G. G. H., \& Pang, T. (2017). The state of tobacco control in ASEAN: Framing the implementation of the FCTC from a health system perspective. Asia $\mathcal{E}$ the Pacific Policy Studies, 5(1), 47-64.

Chaloupka, F. (1991). Rational addictive behavior and cigarette smoking. Journal of political Economy, 99(4), 722-742.

Egbe, C. O., Egbochuku, E. O., Myer-Weitz, A., \& Petersen, I. (2017). A qualitative exploration of the theory of triadic influence in Nigerian setting: The case of cigarette smoking, Psychol Study, 62(3), $314-325$.

Gneiting, U., \& Schmitz, H. P. (2016). Comparing global alcohol and tobacco control efforts: Network formation and evolution in international health governance. Health Policy and Planning, 31(1), 98-109.

Gravely, S., Giovino, G. A., Craig, L., Commar, A., D’Espaignet, E. T., Schotte, K., \& Fong, G. T. (2017). Implementation of key demand-reduction measures of the WHO framework convention on tobacco control and change in smoking prevalence in 126 countries: An association study. The Lancet Public Health, 2(4), 166-174.

Hooper, C. R., \& Aglue, C. (2009). Tobacco regulation: Autonomy up in smoke? Journal of Medical Ethics, 35(6), 365-368.

Huq, I., Nargis, N., Lkhagvasuren, D., Hussain, A. K. M. G., \& Fong, G. T. (2018). The impact of income and taxation in a price-tiered cigarette market- findings from ITC Bangladesh Survey. Tobacco Control,28(3).

Islam, S. M. S., Mainuddin, A. K. M., Bhuiyan, F. A., \& Chowdhury, K. N. (2016). Prevalence of tobacco use and its contributing factors among adolescents in Bangladesh: Results from a population-based 
study. South Asian Journal of Cancer, 5(4), 186.

Kaur, J., \& Jain, D. D. (2011). Tobacco control policies in India: Implementation and challenges. Indian Journal of Public Health, 55(3), 220-227.

Keeler, T. E., Hu, T. W., Barnett, P. G., \& Manning, W. G. (1993). Taxation, regulation, and addiction: A demand function for cigarettes based on time-series evidence. Journal of health economics, 12(1), 1-18.

Lessig, L. (1995). The regulation of social meaning. The University of Chicago Law Review, 62(3), 943-1045.

Levy, D. T., Benjakul, S., Ross, H., \& Ritthiphakdee, B. (2008).The Role of tobacco control policies in reducing smoking and deaths in a middle income nation: results from the Thailand sim-smoke simulation model. Tobacco Control, 17(1), 53-59.

Mackay, J., Ritthiphakdee, B., \& Reddy, K. S. (2013). Tobacco control in Asia. The Lancet, 381(9877), 1581-1587.

Milov, S. (2019). The cigarette: A political history. Harvard university press. Cambridge, MA.

Muggli, M. E., Zheng, A., Liberman, J., Coxon, N., Candler, L., Donley, K., \& Lambert, P. (2014). Tracking the relevance of the WHO Framework Convention on Tobacco Control in legislation and litigation through the online resource, Tobacco Control Laws. Tobacco control, 23(5), 457-460.

O’Donnell, M. J., Chin, S. L., Rangarajan, S., Xavier, D., Liu, L., Zhang, H., \& Lopez-Jaramillo, P. (2016). Global and regional effects of potentially modifiable risk factors associated with acute stroke in 32 countries (INTERSTROKE): a case-control study. The Lancet, 388(10046), 761-775.

Pinto, M., \&Ugá, M. A. D. (2010). The cost of tobacco-related diseases for Brazil's Unified National Health System. Cadernos de SaudePublica, 26(6), 1234-1245.

Riquinho, D. L.,\&Hennington, E. A. (2012). Health, environment and working conditions in tobacco cultivation: a review of the literature. CiênciaESSaúdeColetiva. 17(6), 1587-1600.

Roser,M., \& Ritchie, H. (2018). "Smoking". Published online at our world in data.org. Retrieved from: 'https://ourworldindata.org/smoking' [Online Resource].

Stanley, C. (2017). How smoking and drinking affect the body. Retrieved from https://www.mountelizabeth.com.sg/healthplus/article/how-smoking-and-drinking-affects-the-body on 27.05.2018

Stoklosa, M. (2016). Is the illicit cigarette market really growing? The tobacco industry' misleading math trick. Tobacco Control, 25(3),360-361.

The tobacco atlas. (2016).https://tobaccoatlas.org/topic/consumption/

The tobacco atlas. (2018).https://tobaccoatlas.org/topic/consumption/

United States Department of Health and Human Services. 2014. The Health Consequences of Smoking-50 Years of Progress. U.S. Department of health and human services Public Health Service Office of the Surgeon General Rockville, MD. 
Vardavas, C. I., \&Nikitara, K. (2020). COVID-19 and smoking: A systematic review of the evidence. Tobacco induced diseases, 18.

Wakefield, M., Morley, C., Horan, J. K., \& Cummings, K. M. (2002). The cigarette pack as image: New evidence from tobacco industry documents. Tobacco control, 11(suppl 1), 73-80.

Wasserman, J., Manning, W. G., Newhouse, J. P.,\& Winkler, J. D. (1991). The effects of excise taxes and regulations on cigarette smoking. Journal of Health Economics, 10(1),43-64.

World Health Organization. (2007). Impact of tobacco related diseases in Bangladesh. World Health Organization, Regional Office for South-East Asia. 55(3),155-160.

World Health Organization. (2015). WHO global report on trends in prevalence of tobacco smoking 2015. World Health Organization, 20 Avenue Appia, 1211 Geneva 27, Switzerland.

World Health Organization. (2018).WHO global report on trends in prevalence of tobacco smoking 2015. $2^{\text {nd }}$ edition. World Health Organization, 20 Avenue Appia, 1211 Geneva 27, Switzerland. 


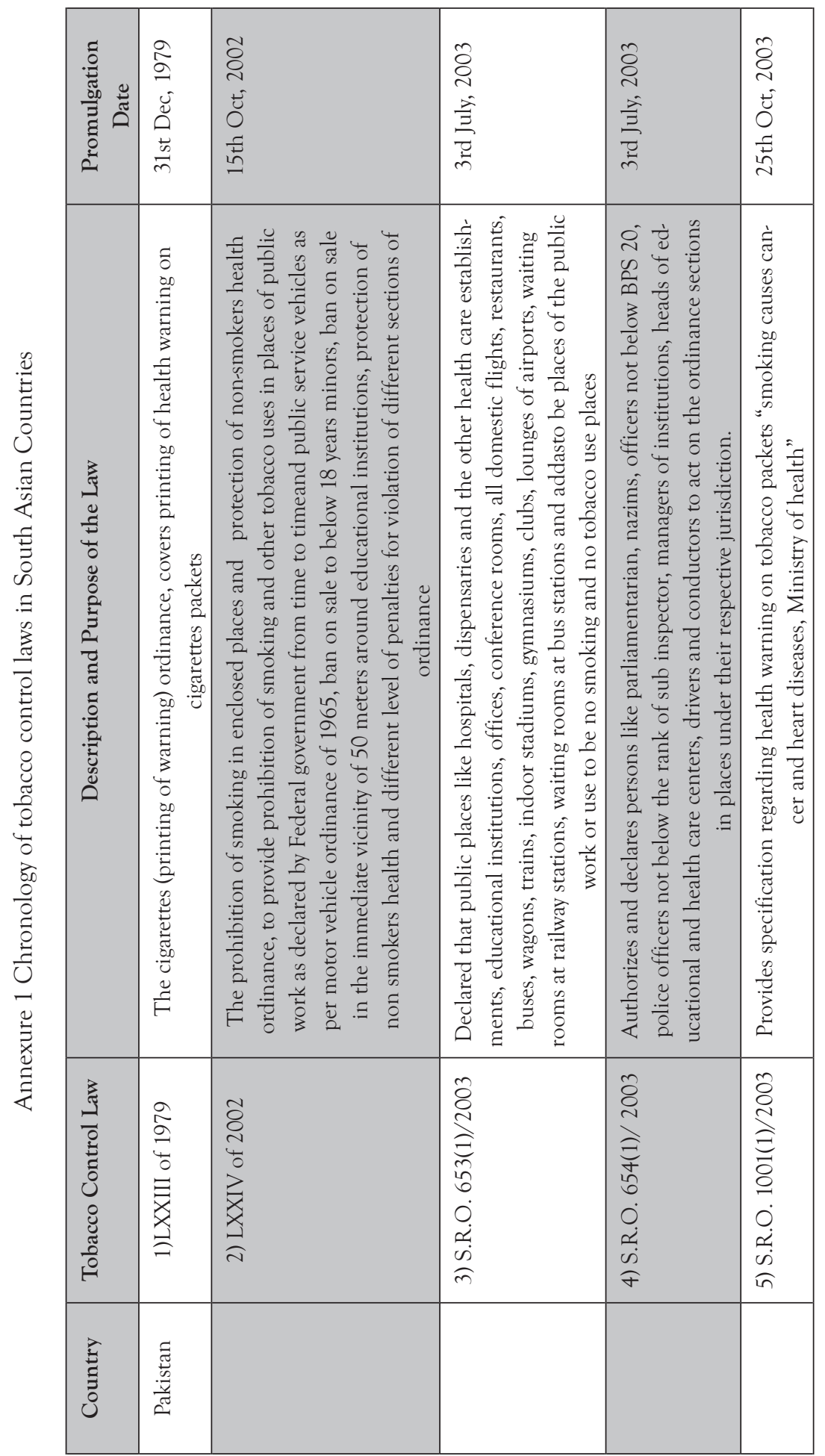




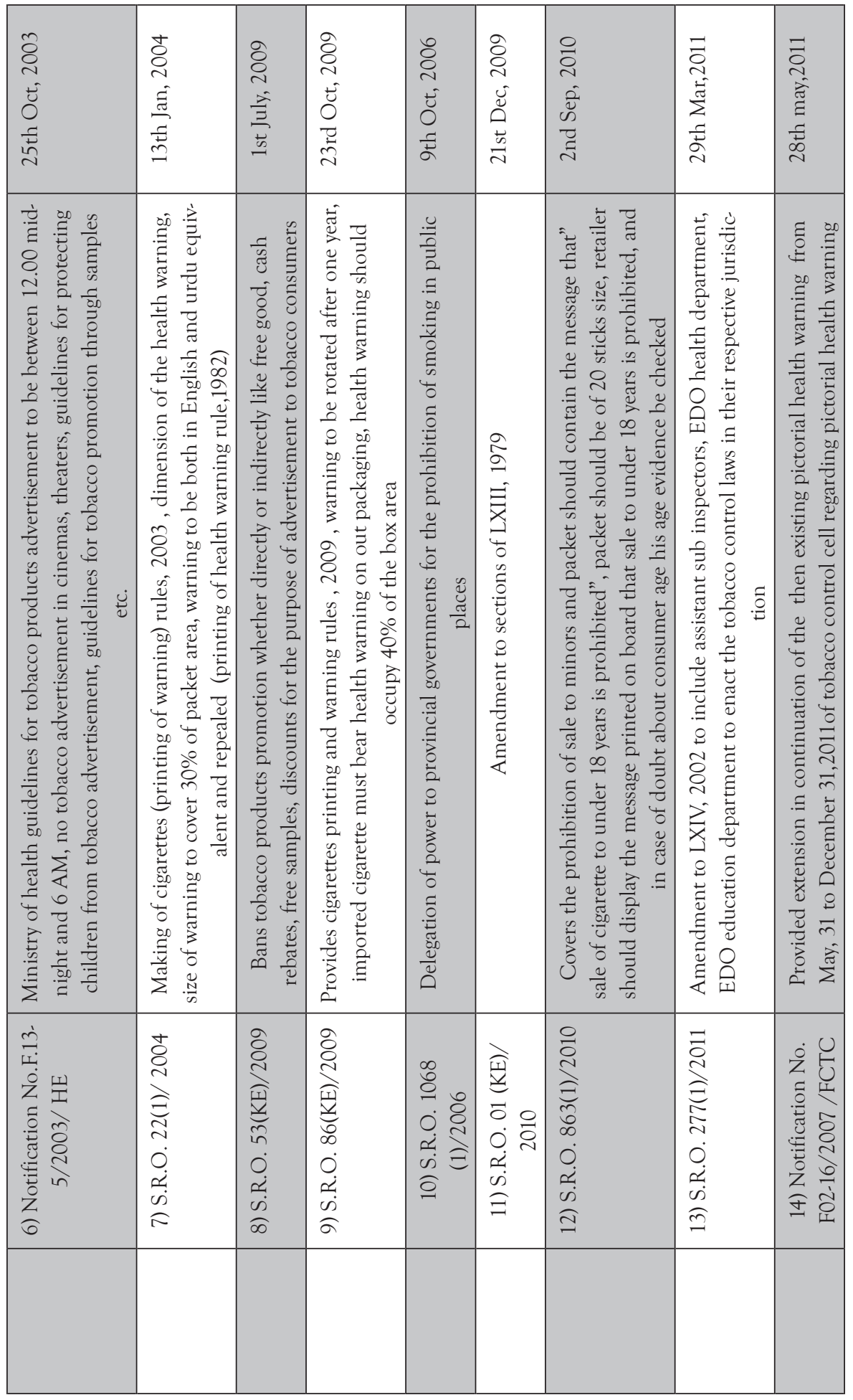




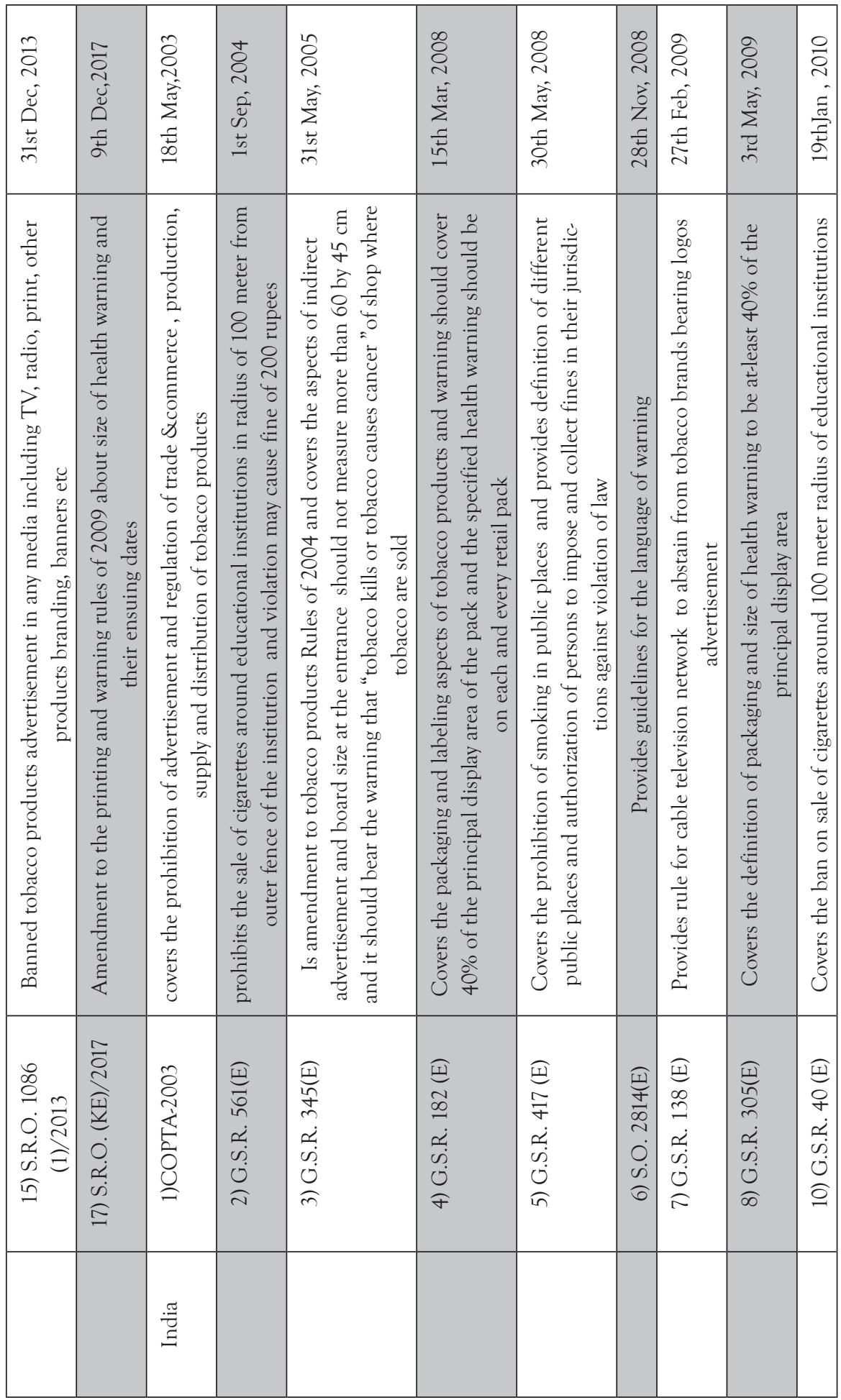




\begin{tabular}{|c|c|c|c|c|c|c|}
\hline 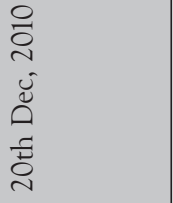 & 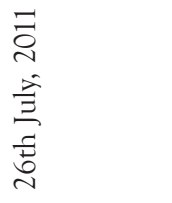 & 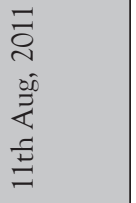 & 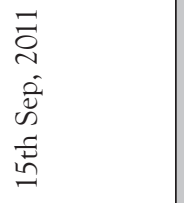 & 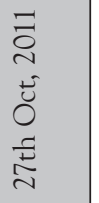 & 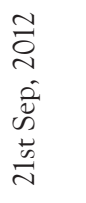 & 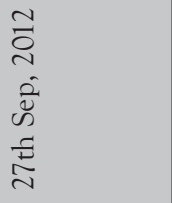 \\
\hline 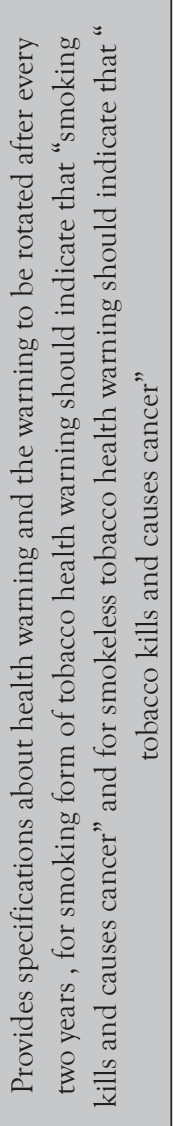 & 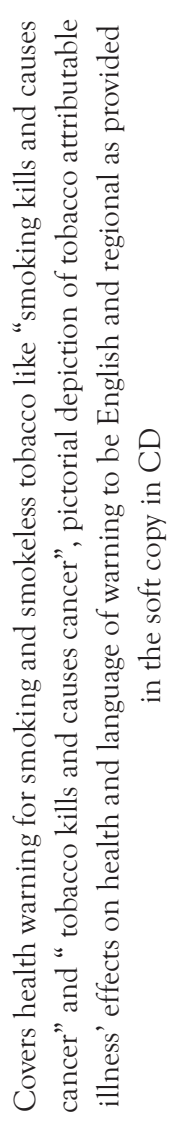 & 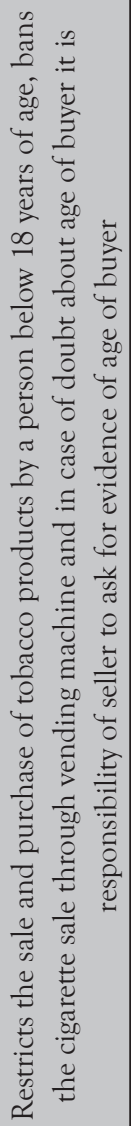 & 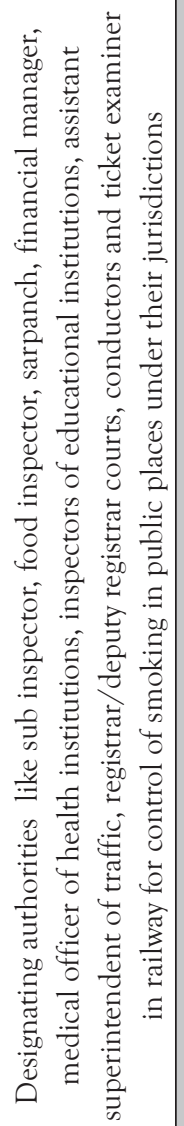 & 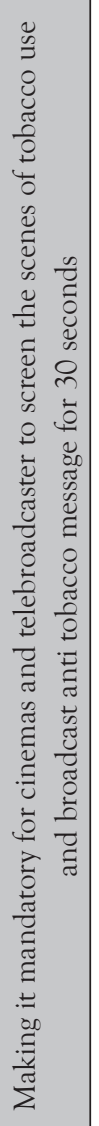 & 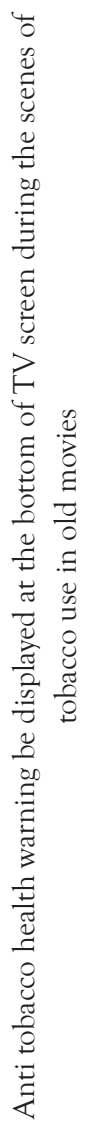 & 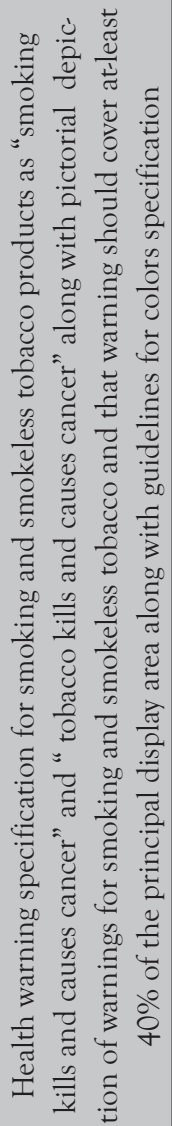 \\
\hline 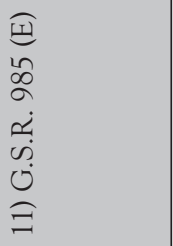 & 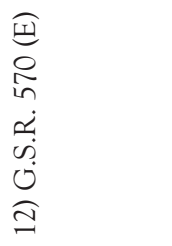 & 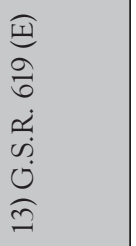 & 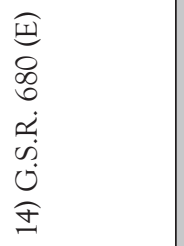 & 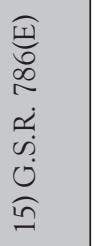 & 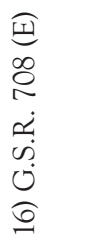 & 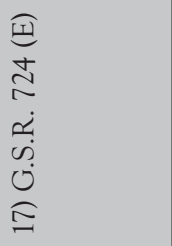 \\
\hline & & & & & & \\
\hline
\end{tabular}




\begin{tabular}{|c|c|c|c|c|c|c|c|}
\hline 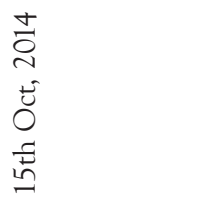 & 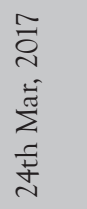 & 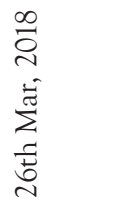 & 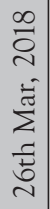 & 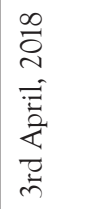 & 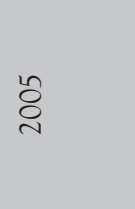 & ঠి & 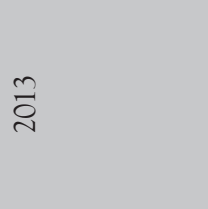 \\
\hline 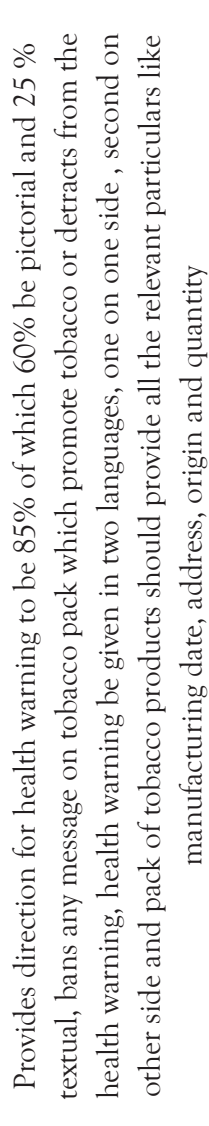 & 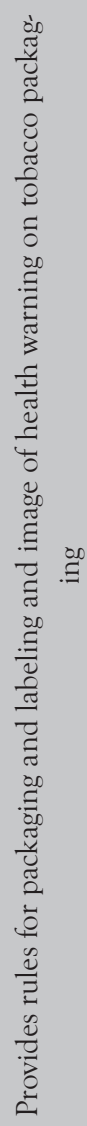 & 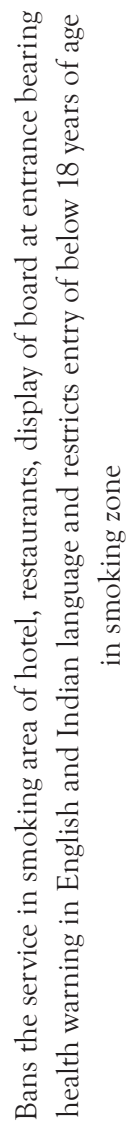 & 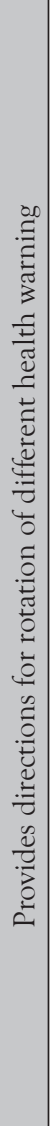 & 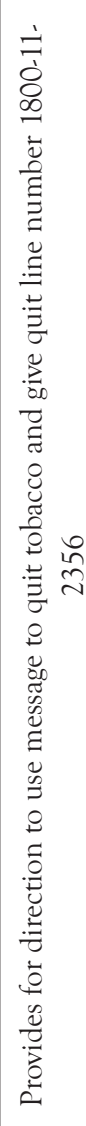 & 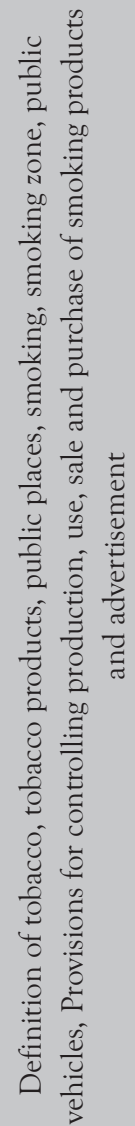 & 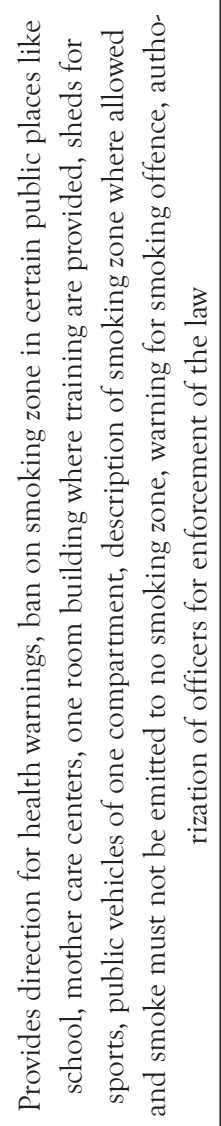 & 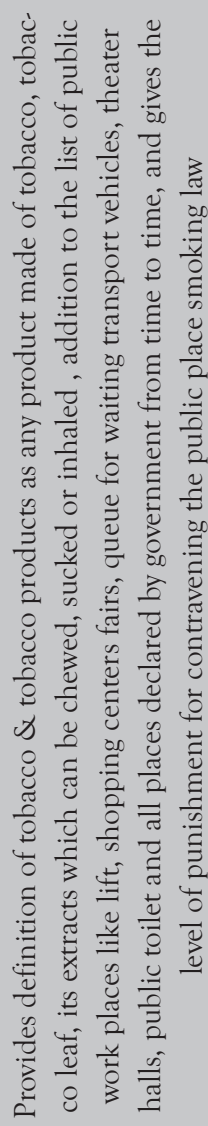 \\
\hline 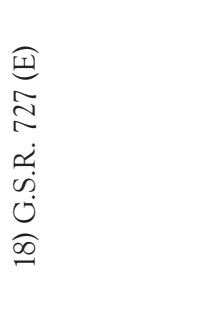 & 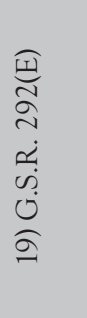 & 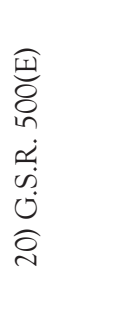 & 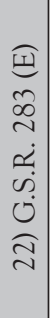 & 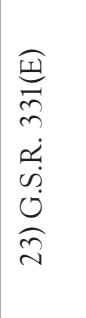 & 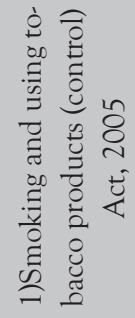 & 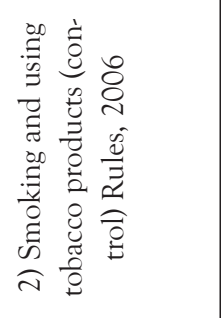 & 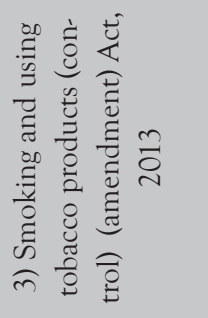 \\
\hline & & & & & 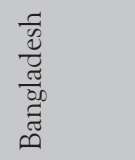 & & \\
\hline
\end{tabular}




\begin{tabular}{|c|c|c|c|c|c|c|}
\hline 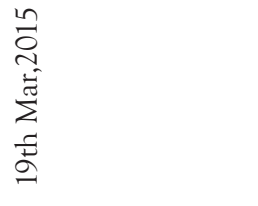 & 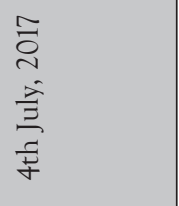 & 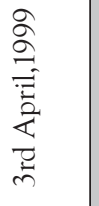 & 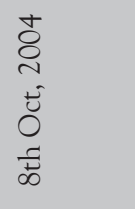 & 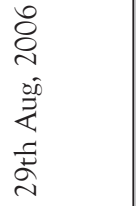 & 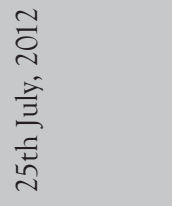 & 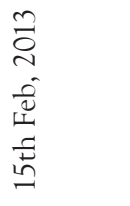 \\
\hline 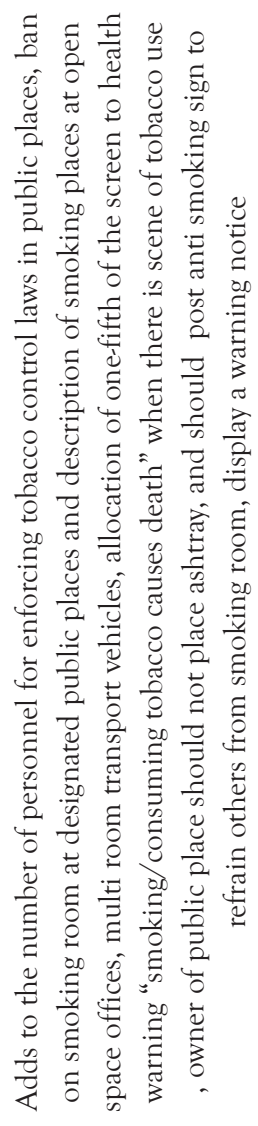 & 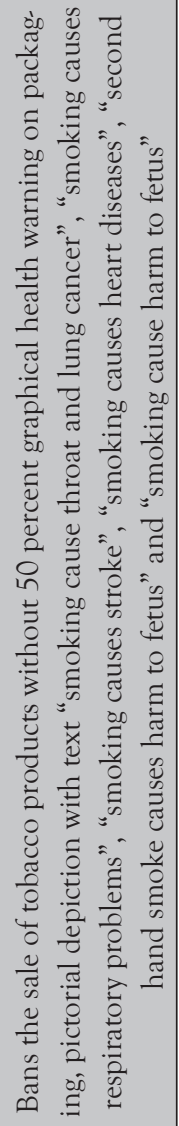 & 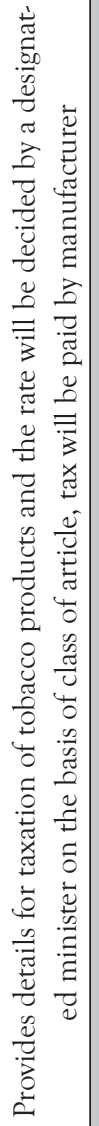 & 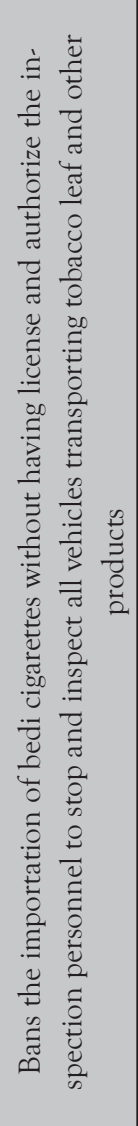 & 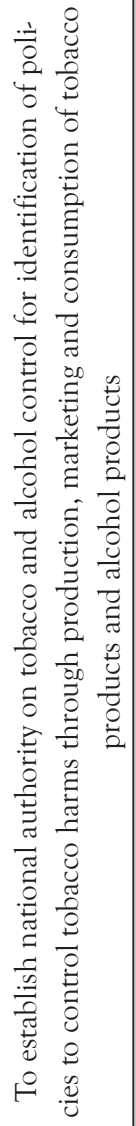 & 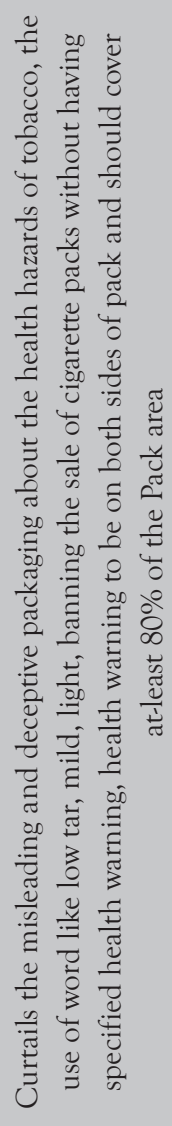 & 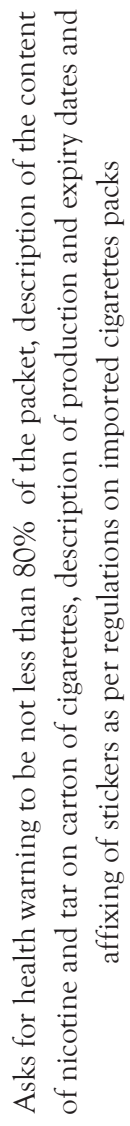 \\
\hline 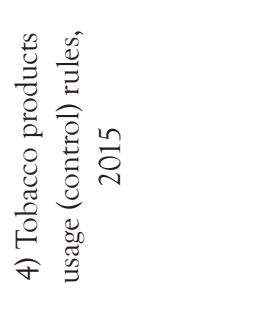 & 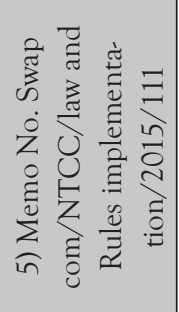 & 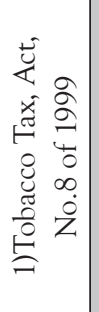 & 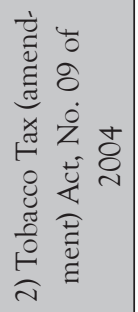 & 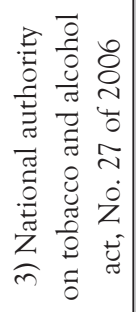 & 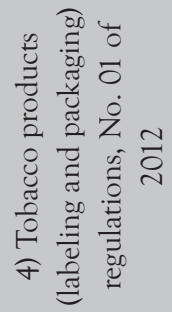 & 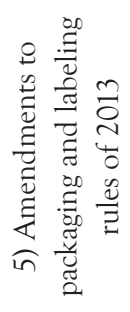 \\
\hline & & & & & & \\
\hline
\end{tabular}




\begin{tabular}{|c|c|c|c|c|}
\hline 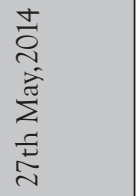 & 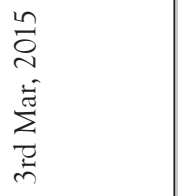 & 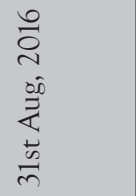 & 음 & 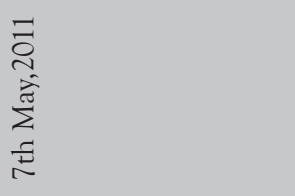 \\
\hline 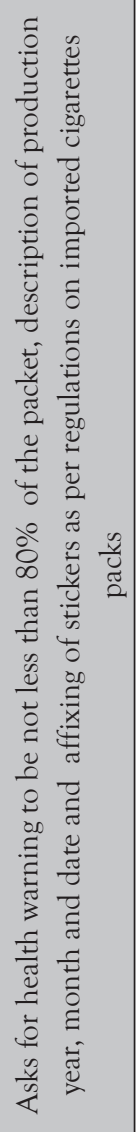 & 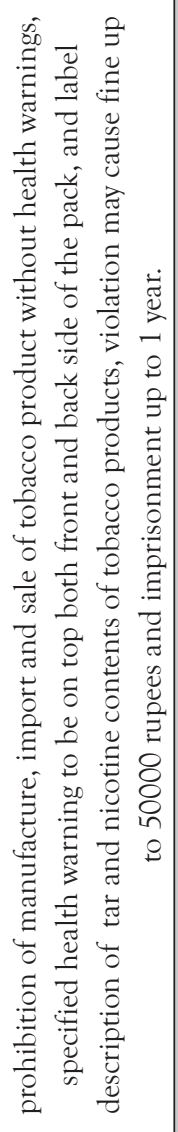 & 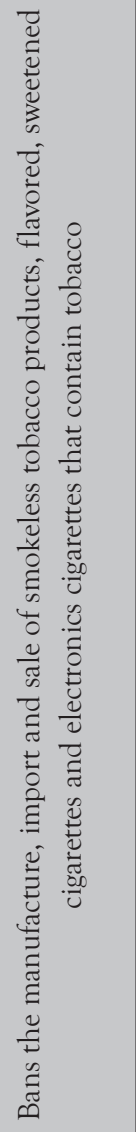 & 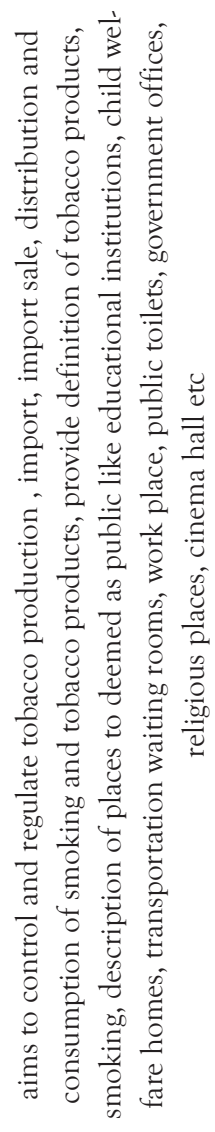 & 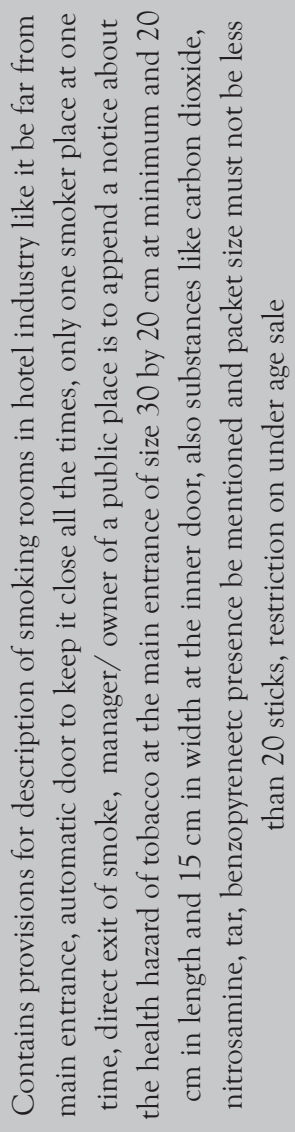 \\
\hline 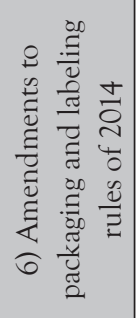 & 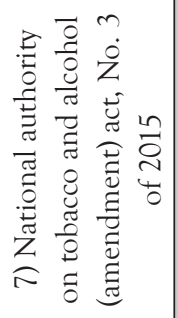 & 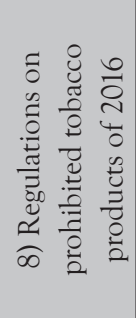 & 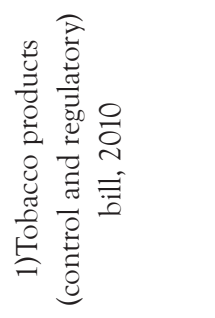 & 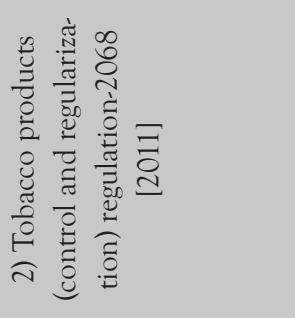 \\
\hline & & & $\frac{\tilde{a}}{\ddot{z}}$ & \\
\hline
\end{tabular}




\begin{tabular}{|c|c|c|c|c|c|}
\hline 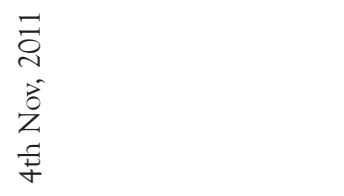 & 党 & 总 & 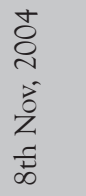 & $\begin{array}{l}n \\
8 \\
0 \\
0 \\
0 \\
1 \\
\pm \\
0\end{array}$ & $\begin{array}{l}\stackrel{0}{0} \\
\text { ป } \\
\stackrel{5}{\Xi} \\
\stackrel{\Xi}{\Xi} \\
\stackrel{\Xi}{0}\end{array}$ \\
\hline 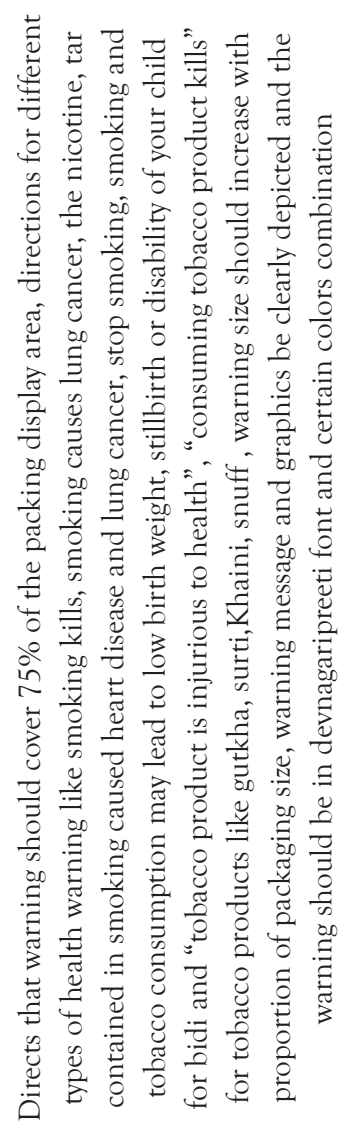 & 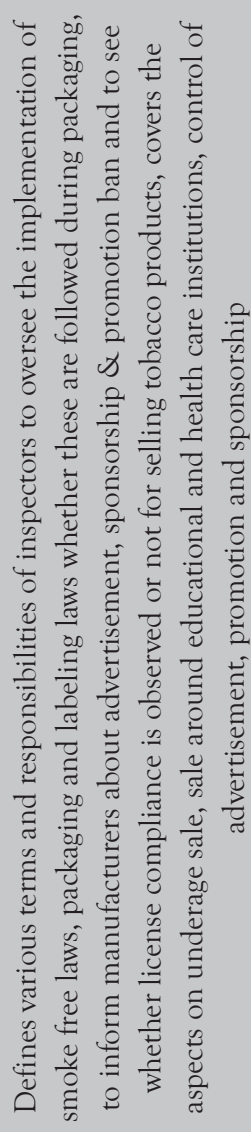 & 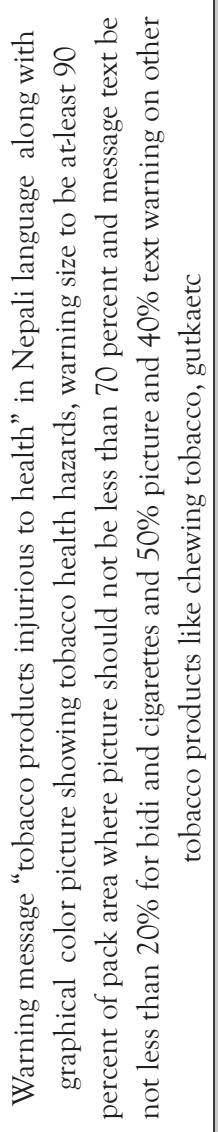 & 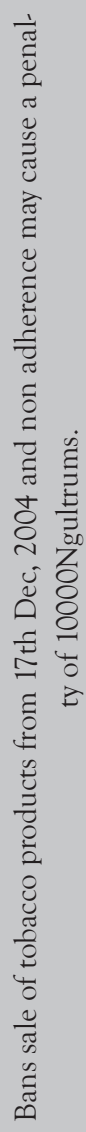 & 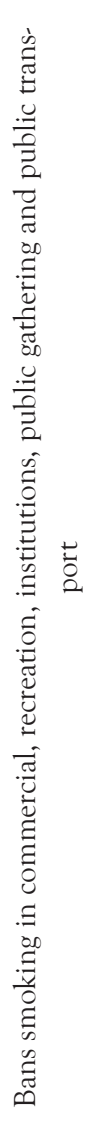 & 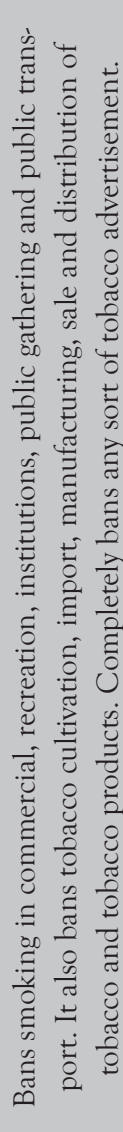 \\
\hline 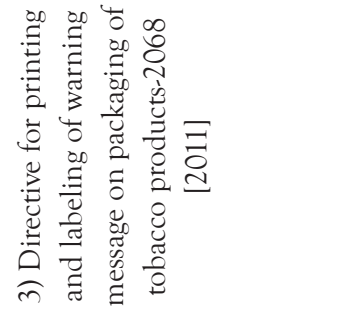 & 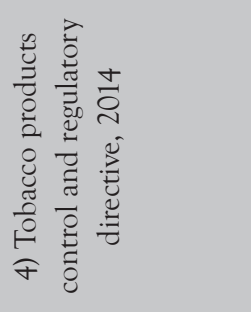 & 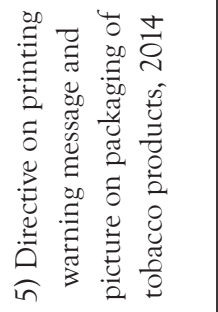 & 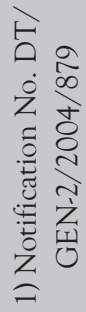 & 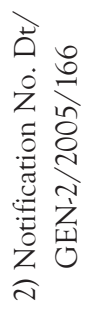 & 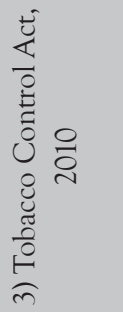 \\
\hline & & & & & \\
\hline
\end{tabular}




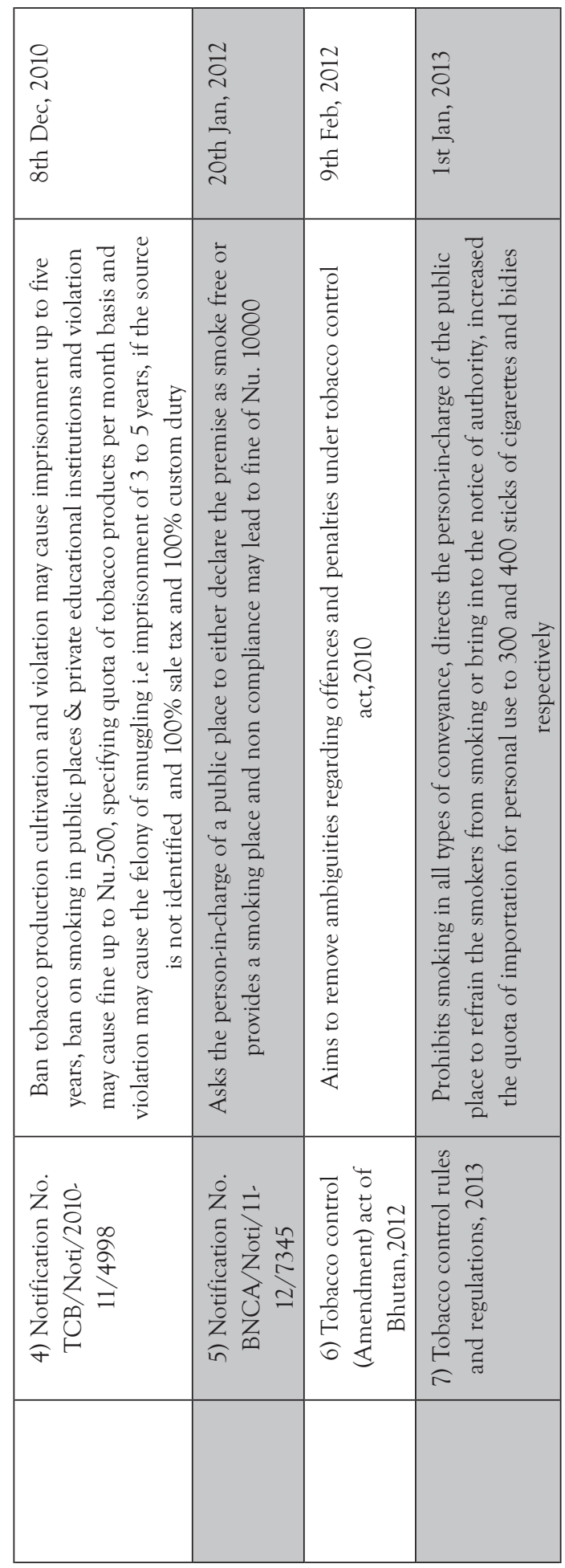

